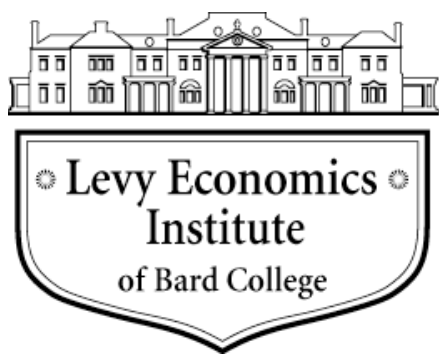

Working Paper No. 596

\title{
Infinite-variance, Alpha-stable Shocks in Monetary SVAR
}

\author{
by \\ Greg Hannsgen* \\ Levy Economics Institute of Bard College
}

April 2010 (revised April 28)

* This paper is a greatly revised and expanded version of Hannsgen (2008) with some new results. The author wishes to thank Olivier Blanchard, an associate editor, and anonymous referees for comments on previous drafts that led to many substantial improvements in the paper. Also, he thanks those who attended a seminar at the Levy Institute, many of whom provided interesting and helpful comments. The author is also grateful to John Nolan for answering statistical questions and for making his STABLE software available on his webpage (see footnote 15). Discussions with Greg Colman and Kenneth Hannsgen led to what are hopefully improvements in the explanations and arguments in this paper. Though grateful, the author has not followed all of the advice provided by these scholars.

The Levy Economics Institute Working Paper Collection presents research in progress by Levy Institute scholars and conference participants. The purpose of the series is to disseminate ideas to and elicit comments from academics and professionals.

Levy Economics Institute of Bard College, founded in 1986, is a nonprofit, nonpartisan, independently funded research organization devoted to public service. Through scholarship and economic research it generates viable, effective public policy responses to important economic problems that profoundly affect the quality of life in the United States and abroad.

Levy Economics Institute P.O. Box 5000

Annandale-on-Hudson, NY 12504-5000

http://www.levyinstitute.org

Copyright (C Levy Economics Institute 2010 All rights reserved 


\begin{abstract}
The process of constructing impulse-response functions (IRFs) and forecast-error variance decompositions (FEVDs) for a structural vector autoregression (SVAR) usually involves a factorization of an estimate of the error-term variance-covariance matrix V. Examining residuals from a monetary VAR, this paper finds evidence suggesting that all of the variances in $\mathrm{V}$ are infinite. Specifically, this study estimates alpha-stable distributions for the reducedform error terms. The ML estimates of the residuals' characteristic exponents $\alpha$ range from 1.5504 to 1.7734 , with the Gaussian case lying outside 95 percent asymptotic confidence intervals for all six equations of the VAR. Variance-stabilized P-P plots show that the estimated distributions fit the residuals well. Results for subsamples are varied, while GARCH(1,1) filtering yields standardized shocks that are also all likely to be non-Gaussian alpha stable. When one or more error terms have infinite variance, V cannot be factored. Moreover, by Proposition 1, the reduced-form DGP cannot be transformed, using the required nonsingular matrix, into an appropriate system of structural equations with orthogonal, or even finite-variance, shocks. This result holds with arbitrary sets of identifying restrictions, including even the null set. Hence, with one or more infinite-variance error terms, structural interpretation of the reduced-form VAR within the standard SVAR model is impossible.
\end{abstract}

Keywords: Structural Vector Autoregression; VAR; Lévy-stable Distribution; Infinite Variance; Monetary Policy Shocks; Heavy-tailed Error Terms; Factorization; Impulse Response Function; Transformability Problem

JEL Classifications: C32, C46, E30, E52 


\section{INTRODUCTION}

Since the seminal article on structural vector autoregressions (SVARs) by Sims (1980), macroeconomists have used these econometric models to quantify the economic effects of monetary-policy shocks. SVARs are now used in a wide variety of applications, ranging from studies of the effects of fiscal- and monetary-policy shocks to tests of dynamic, stochastic general equilibrium models. This paper seeks to find out whether one or more innovations (or equivalently, shocks or error terms) in one illustrative monetary SVAR has infinite unconditional variance, or formally (Feller 1971: 133-134):

$$
\sigma_{\varepsilon_{i t}}^{2} \equiv \int_{-\infty}^{\infty} \varepsilon^{2} d F_{i}(\varepsilon)=\infty
$$

where $\varepsilon_{\mathrm{it}}, 1,2,3, \ldots \mathrm{T}$, are the error terms in the equation for some variable $\mathrm{i}$ in the reducedform of a VAR data-generating process (DGP) and $\mathrm{F}_{\mathrm{i}}(\varepsilon)$ is their unconditional distribution. Infinite-variance error terms would obviously complicate estimation, testing, and inference in any regression equation. This paper focuses on a potential problem that arises specifically in SVAR analysis because of the requirement that the reduced-form DGP be transformable into a structural form. Usually, an estimate of the matrix $\mathrm{V}=\mathrm{E}\left(\varepsilon_{\mathrm{t}} \varepsilon_{\mathrm{t}}^{\prime}\right)$ where $\varepsilon_{\mathrm{t}}=\left(\varepsilon_{1 \mathrm{t}}, \varepsilon_{2 \mathrm{t}}, \varepsilon_{3 \mathrm{t}}, \ldots \varepsilon_{\mathrm{it}}\right.$, $\left.\ldots . . . \varepsilon_{\mathrm{kt}}\right)^{\prime}$ is needed to achieve this transformation. The nonexistence of $\mathrm{V}$ implies the nonexistence of the structural representation, as shown in Proposition 1 below. In this paper, evidence is presented from a monetary SVAR supporting the hypothesis that for one or more equations $\mathrm{i}$, the error term $\varepsilon_{\mathrm{it}}$ has an alpha-stable, infinite-variance distribution $\mathrm{F}_{\mathrm{i}}$.

The rest of the paper is organized as follows. Section II provides background on alphastable distributions. Section III presents a standard SVAR model and argues that infinitevariance reduced-form shocks preclude most standard structural interpretations of VARs. Section IV discusses the literature on alpha-stable distributions, macro SVARs, and the connections between them. Section V is a discussion of this paper's monetary SVAR, including the data, specification, results, and residuals. Section VI reports estimates of the characteristic exponent $\alpha$ of the error term in each equation of the VAR for both the full sample and two subsamples, and assesses the fit of the estimated alpha-stable distributions. Then, 
attempting to measure the characteristic exponents independently of the influence of timevarying dispersion, the paper reports results in section VII for GARCH-filtered shocks. Section VIII draws together the main findings of the paper and suggests some implications.

\section{ALPHA-STABLE DISTRIBUTIONS}

The many special statistical properties of alpha-stable random variables offer some theoretical reasons for the use of alpha-stable error terms in an econometric model (Bartels 1977) and suggest why alpha-stable distributions have been found in many kinds of scientific and financial data. In addition to those below, more are proven and discussed in references on the subject, such as Nolan (forthcoming) and Samorodnitsky and Taqqu (1994).

Stable random variables are the only possible limiting distributions for sums of i.i.d. shocks. That is, a random variable $\mathrm{X}$ has a stable distribution if it has a domain of attraction, i.e., if there is a sequence of i.i.d. random variables $Y_{1}, Y_{2}, \ldots$ and sequences of positive numbers $\left\{\mathrm{d}_{\mathrm{n}}\right\}$ and real numbers $\left\{\mathrm{a}_{\mathrm{n}}\right\}$, such that

$\frac{Y_{1}+Y_{2}+\ldots+Y_{n}}{d_{n}}+a_{n} \stackrel{d}{\Rightarrow} X$

where the arrow symbol means "converges in distribution to" as the sample size $\mathrm{n} \rightarrow \infty$ (Samorodnitsky and Taqqu 1994: 5). If the Y's have a finite variance, $\mathrm{X}$ is normally distributed.

Furthermore, there is an equivalent definition: a random variable $\mathrm{X}$ has a stable distribution if for each $\mathrm{n}$ greater than or equal to 2 , the distribution of a sum of $\mathrm{n}$ independent copies of $\mathrm{X}$, denoted $\mathrm{X}_{1}, \mathrm{X}_{2}, \ldots . \mathrm{X}_{\mathrm{n}}$, is the same as that of an affine transformation of $\mathrm{X}$ involving a positive scalar $\mathrm{C}_{\mathrm{n}}$ and a scalar $\mathrm{D}_{\mathrm{n}}$ :

$$
X_{1}+X_{2}+\ldots+X_{n} \stackrel{d}{=} C_{n} X+D_{n}
$$

(Samorodnitsky and Taqqu 1994: 3). It turns out that

$$
C_{n}=n^{1 / \alpha}
$$


where $\alpha$ is a parameter known as the characteristic exponent or stable index of the distribution, which plays a major role in this paper. Alpha takes on values in the interval $(0,2]$, with lower $\alpha$ 's indicating distributions with higher peaks and thicker tails. Along with $\alpha$, stable distributions have three other parameters: $\beta$ for skew, $\gamma$ for scale, and $\delta$ for location. A normal distribution is a stable distribution with $\alpha=2$ and $\beta=0$. Figure 1 shows the standard normal distribution and a symmetric, stable distribution of the same scale with $\alpha=1.7$. (All figures and tables are at end of this paper.)

Crucially, when $\alpha<2$, the non-Gaussian case, the variance of an alpha-stable random variable equals infinity. When a VAR error term has a distribution with infinite variance, the consequences for SVAR analysis are serious indeed and go far beyond those caused by the presence of finite-variance, thick-tailed residuals.

\section{THE NONEXISTENCE OF STRUCTURAL REPRESENTATIONS OF VARS WITH ONE OR MORE INFINITE-VARIANCE ERROR TERMS}

This paper examines the implications for SVARs of infinite-variance innovations. ${ }^{1}$ To see these implications, recall that the structural form of a VAR model of order $p$ is

$$
A Y_{t}=B_{1} Y_{t-1}+B_{2} Y_{t-2}+\ldots .+B_{p} Y_{t-p}+\eta_{t}
$$

where $A$ and the $B_{i} s$ are k-by-k matrices of parameters, with $A$ nonsingular; the $Y_{t} s, t=1,2$, $3 \ldots . ., \mathrm{T}$, are $\mathrm{k}$-component vectors of economic variables at time $\mathrm{t}$; and $\eta_{\mathrm{t}}$ is a $\mathrm{k}$-component vector of structural shocks. Presample values $\mathrm{Y}_{-\mathrm{p}}, \mathrm{Y}_{-(\mathrm{p}-1)}, \ldots, \mathrm{Y}_{-1}$ are given.

SVAR uses a set of distributional assumptions about the structural shock vector like the following:

$$
\begin{aligned}
& E\left(\eta_{t}\right)=0 \\
& E\left(\eta_{t} \mid Y_{t-1}, Y_{t-2}, \ldots, Y_{t-p}\right)=0 \\
& E\left(\eta_{t} \eta_{s}{ }^{\prime}\right)=I \text { for } t=s \\
& =0 \text { for } t \neq s
\end{aligned}
$$

\footnotetext{
${ }^{1}$ Hamilton (1994), Lütkepohl (2006), and Watson (1994) provide standard treatments of SVARs.
} 
where I is the k-by-k identity matrix. ${ }^{2}$ An estimate of the structural form (1) is indispensible for much of the work that is done with VARs. This paper focuses on cases in which the structural form (1) does not exist, in the sense that the distribution of the error terms in the reduced form below implies that the set of parameters in (1) does not exist, regardless of any further assumptions that are made, as made clear below. The parameters and the structural shock vectors $\eta_{t}, t=1,2,3, \ldots, T$, of (1) are usually identified from the reduced form ${ }^{3}$

$Y_{t}=C_{1} Y_{t-1}+C_{2} Y_{t-2}+\ldots .+C_{p} Y_{t-p}+\varepsilon_{t}$

where

$\forall j$ and $t$,

$C_{j}=A^{-1} B_{j}$

$\varepsilon_{t}=A^{-1} \eta_{t}$

The covariance matrix of $\varepsilon_{\mathrm{t}}$ is

$V=E\left(\varepsilon_{t} \varepsilon_{t}{ }^{\prime}\right)=E\left(A^{-1} \eta_{t} \eta_{t}{ }^{\prime} A^{-1}{ }^{\prime}\right)=A^{-1} A^{-1}{ }^{\prime}$

This leads to a relationship between the structural shocks and reduced-form error terms: $\eta_{t}=A \varepsilon_{t}$

To find the needed parameter and shock estimates, one first estimates the reduced form (2). ${ }^{4}$ The residuals $\varepsilon_{t}{ }^{*}$ from the estimated system are consistent estimates of the shocks $\varepsilon_{t}$, but the most important uses of SVARs require that we identify the $\eta_{t}$. To do this, one first obtains an estimate $\mathrm{V}^{*}$ of the covariance matrix $\mathrm{V}$. Then, under the identifying assumption that $\mathrm{A}$ is

\footnotetext{
${ }^{2}$ Many studies make more specific distributional assumptions about the disturbance term $\eta_{\mathrm{t}}$, especially for maximum likelihood estimation (Hamilton 1994: 291-302). Also, $\mathrm{E}\left(\eta_{\mathrm{t}} \eta_{\mathrm{t}}{ }^{\prime}\right)$ is sometimes assumed to be an arbitrary diagonal matrix, rather than the identity matrix.

${ }^{3}$ Stability requires that the inverse characteristic roots of the system (2) lie outside the complex unit circle.

${ }^{4}$ Given the assumptions above, equation-by-equation OLS estimation (LS) yields a consistent estimate of the regression parameters. LS is identical to the seemingly unrelated regressions (SUR) estimator in this case, so it is also the efficient generalized least squares (GLS) estimator. See Davidson and MacKinnon (2004: especially 595597) or Hamilton (1994: 291-350), and the references therein for more details. Bayesian estimators are often used as well (for example, see Leeper, Sims, and Zha [1996]).
} 
lower triangular, that matrix can be identified by decomposing $\mathrm{V}^{*}$ into the product of a lower triangular matrix $\mathrm{A}^{*-1}$ and its transpose $\mathrm{A}^{*-1}$ (the Cholesky factorization) and inverting. Estimates of the $\eta_{t}$ can then be identified from the relationship

$\eta_{t}^{*}=A^{*} \varepsilon_{t}^{*}$

Subsequent to Sims's (1980) article, macroeconomists developed patterns of zero restrictions that do not result in a triangular A matrix (Bernanke 1986; Blanchard and Watson 1986; and Sims 1986), as well as long-run restrictions (Blanchard and Quah 1989). All of these SVAR identification schemes, and most others developed subsequent to Sims (1980), involve factorizations of $\mathrm{V}$ similar to (4). They are usually estimated by factoring $\mathrm{V}^{*}$. (An instrumental-variables estimator for SVARs with long-run restrictions is presented in Shapiro and Watson [1989]. Proposition 1 below applies to this case as well.)

The two main uses of the structural estimates are:

1. Impulse response functions (IRFs) derived from the structural moving average representation

$$
Y_{t}=D_{1} \eta_{t}+D_{2} \eta_{t-1}+D_{3} \eta_{t-1}+\ldots
$$

which measure the effects over time of a one-unit or one-standard-deviation shock to one component of $\eta_{\mathrm{t}}$, and

2. Forecast error variance decompositions (FEVDs), which reveal the proportion of the variation of each variable in $Y_{t}$ that is due to variation in each element of $\eta_{t}$.

Through the use of appropriate identifying restrictions, the structural shocks $\eta_{\mathrm{it}}{ }^{*}$ can be interpreted as estimates of monetary policy shocks, money demand shocks, technology shocks, and the like. The $\varepsilon_{\mathrm{it}}{ }^{*}$ are not as useful, because, being correlated, they do not lend themselves as easily to structural interpretations.

When the covariance matrix $\mathrm{V}$ has one or more infinite diagonal components, the decomposition $\mathrm{V}=\mathrm{A}^{-1} \mathrm{~A}^{-1}$ does not exist, and hence the structural form (1) is not an 
appropriate model. ${ }^{5}$ All elements of the estimate $\mathrm{V}^{*}$ will of course be finite, but the term "estimate" is not appropriate when V does not exist. Hence, if the distribution of any component of $\varepsilon_{\mathrm{t}}$ is stable with $\alpha<2$, implying infinite variance, there is no meaningful estimate of the structural shocks and coefficients in the structural form (1) ${ }^{6}$, making IR and FEVD analysis impossible.

A more rigorous statement of the existence problem posed for SVAR by infinitevariance innovations might be of help. One reason is that the critique proposed here might seem only to call for different estimators of A and the rest of the structural DGP that do not make use of a factorization of $V^{*}$ (e.g., Shapiro and Watson 1989). In fact, though, there exists no nonsingular A that transforms the innovations $\varepsilon_{\text {it }}$ into orthogonal shocks $\eta_{\text {it }}$ when one or more equations $i$ has innovations with infinite variance, $\sigma_{i}{ }^{2}$. This is shown in the following proposition.

PROPOSITION 1: Let $\varepsilon_{t}$ and $\eta_{t}$ be two random $k$-element vectors and let $A$ be a $k$-by$k$ nonsingular matrix of real numbers, with $\eta_{t}=A \varepsilon_{t}$. If one or more of the elements of $\varepsilon_{t}$ has infinite variance, then

$E\left(\eta_{t} \eta_{t}{ }^{\prime}\right) \neq I$

The proposition still holds if the identity matrix I above is replaced by any other finite $k$-by-k matrix $W$.

Proof: We have

$\varepsilon_{t}=A^{-1} \eta_{t}$

We shall assume that at least one element of $\varepsilon_{t}$ has infinite variance and that, as above, $E\left(\eta_{t} \eta_{t}{ }^{\prime}\right)$ $=I($ or $=W)$, and proceed until we find a contradiction. Without loss of generality, assume that the first element of $\varepsilon_{t}$ has infinite variance. The first equation in the system (5) can then be written

\footnotetext{
${ }^{5}$ Also, if more than one innovation has infinite variance, some off-diagonal entries in the variance-covariance matrix will be infinite.

${ }^{6}$ Another issue is the efficient estimation of the reduced-form VAR coefficients when some error variances are infinite. This point seems moot in the context of standard SVAR, for the reasons given in this section.
} 
$\varepsilon_{1 t}=a_{11} \eta_{1 t}+a_{12} \eta_{2 t}+\ldots .+a_{1 k} \eta_{k t}$

where the $a_{1 \mathrm{r}}$ are the elements of the top row of $A^{-1}$ and the $\eta_{j t}$ are the elements of $\eta_{t}$. Then, the variance of $\varepsilon_{1 t}$ is

$\operatorname{var}\left(\varepsilon_{1 t}\right)=a_{11}^{2} \operatorname{var}\left(\eta_{1 t}\right)+a_{12}^{2} \operatorname{var}\left(\eta_{2 t}\right)+\ldots .+a_{1 k}^{2} \operatorname{var}\left(\eta_{k t}\right)+2 a_{11} a_{12} \operatorname{cov}\left(\eta_{1 t}, \eta_{2 t}\right)+$ $2 a_{11} a_{13} \operatorname{cov}\left(\eta_{1 t}, \eta_{3 t}\right)+\ldots .+2 a_{1 k} a_{1(k-2)} \operatorname{cov}\left(\eta_{k t}, \eta_{(k-2) t}\right)+2 a_{1 k} a_{1(k-1)} \operatorname{cov}\left(\eta_{k t}, \eta_{(k-1) t}\right)$

Since by assumption the left side of (6) is infinite, at least one term on the right side must be infinite. But since $E\left(\eta_{t} \eta_{t}{ }^{\prime}\right)=I$, the right-hand side of (6) equals $k$. This is a contradiction. The weaker assumption $E\left(\eta_{t} \eta_{t}{ }^{\prime}\right)=W$, where $W$ is an arbitrary finite matrix, obviously implies a similar contradiction. Q.E.D.

Thus, when at least one innovation $\varepsilon_{\mathrm{it}}$ has infinite variance, no suitable transformation A exists that can generate structural shocks $\eta_{\text {it }}$ satisfying the crucial identifying condition of orthogonality, or for that matter having any covariance matrix called for by a structural model. In other words, when the reduced-form model shown in (2) has one or more equations with infinite-variance shocks, there exists no corresponding structural representation like (1). It is a simple matter to show that this transformability problem arises in a wide range of standard SVAR models, such as the A, B, and AB models presented in Lütkekpohl (2006: 358-368), when for one or more $i$, the variance $\sigma_{i}^{2}$ of $\varepsilon_{i t}$ in (2) is infinite.

\section{REVIEW OF THE LITERATURE}

Alpha-stable distributions are generally attributed to work early in the twentieth century by Paul Lévy. A classic source on the topic is Feller (1971); Nolan (forthcoming) and Samorodnitsky and Taqqu (1994) are more recent monographs. The use of alpha-stable distributions for economic variables began with Mandelbrot's (1963) analysis of securities price changes. Later work by Fama (1963, 1965a, 1965b) and Mandelbrot (1967) found many characteristic exponents below 2 in financial-market data. Blattberg and Gonedes (1974) argued that student's-t distributions better fit some financial series, while Clark (1973) presented one of the first arguments that a heteroskedastic, finite-variance model could better 
account for many thick-tailed unconditional distributions like those observed by Mandelbrot and Fama.

Granger and Orr (1972) analyzed the implications of alpha-stable distributions for time series analysis. Rachev, Kim, and Mittnik (1997) and DasGupta and Mishra (2004) reviewed findings on the econometrics of non-Gaussian stable distributions. Bartels (1977) makes an interesting case for the use of stable distributions in regression analysis. Andrews, Calder, and Davis (2009), Bhansali (1993), Cline (1989), Hannan and Kanter (1977), Kanter and Steiger (1974), and Yohai and Maronna (1977) discuss the estimation of single-equation regressions and autoregressions with alpha-stable shocks. Mirowski (1990) discussed the history of these distributions in economics.

The SVAR literature in macroeconomics and time series econometrics is vast, with thousands of studies employing the technique since 1980. Few if any have made use of alphastable distributional assumptions. Two key references on SVAR modeling and estimation are Hamilton (1994) and Lütkepohl (2006). Christiano, Eichenbaum, and Evans (1999) give an account of what had been learned by late last century from monetary SVARs. Some monetary SVARs using variables, specifications, and estimators similar to the one in this paper include Bernanke and Mihov (1998b), Christiano, Eichenbaum, and Evans (1996), and Strongin (1995). These articles are discussed by Leeper, Sims, and Zha (1996: 29-39). Galí (1999) studies technology shocks using SVAR.

This paper is not meant as an analysis or discussion of any particular study or article. Rather, the example VAR in this paper is meant to be broadly representative of a large swath of the monetary SVAR literature.

Many recent articles have modeled thick-tailed behavior of monetary VAR shocks with many forms of time-varying variances, including stochastic volatility, normal mixtures, and Markov regime-switching models. Some articles in this literature are Cogley and Sargent (2005), Gambetti, Pappa, and Canova (2008), Primiceri (2005), Lanne and Lutkepohl (2008 and 2010), Sims, Waggoner, and Zha (2008), and Sims and Zha (2006). Some of these approaches do not yield the standard, time-invariant IRFs and FEVDs that are so crucial to standard SVAR analysis. Also, modeling heteroskedasticity often markedly increases the number of free parameters to be estimated.

In a statistics journal, J.B. Hill (2006: 3) mentions the possibility that VAR shocks could have infinite variance, leading to problems with orthogonalization for SVAR analysis. 
His article develops alternative projections and decompositions in a large class of non- $\mathrm{L}_{2}$ spaces and characterizes the best predictors in such settings, allowing him to extend work by Gallant, Rossi, and Tauchen (1993) and Koop, Pesaran, and Potter (1996) on nonlinear IRFs to situations with possibly infinite variance. Some of the spaces studied by Hill contain stable, non-Gaussian random variables. Hill's article does not introduce any SVAR applications.

Apparently, other than Hill, few have considered the possibility that VAR residuals or shocks of any kind might have infinite-variance distributions. Zarepour and Roknossadati (2008) may be the only prior study of a VAR model with stable, non-Gaussian shocks, and they restrict their attention to a VAR with unit roots and with one lag of the dependent variable serving as the sole regressor in each equation.

Standard presentations of SVAR assume a finite covariance matrix V, but despite some reports of thick tails in the literature, it is probable that no previous study has examined in detail the evidence for and implications of infinite variance in the error terms of an SVAR. ${ }^{7}$ This paper does so by fitting alpha-stable distributions to reduced-form VAR residuals in raw and GARCH-filtered form, and reporting estimated stable-distribution parameters, along with variance-stabilized P-P plots.

Some references to the literature on methods of estimating the characteristic exponent $\alpha$ are provided at the beginning of section VI.

\section{THE RESERVES VAR: DATA, MODEL, ESTIMATION, RESULTS, AND RESIDUALS}

The data are monthly and span the period January 1959-November 2007. The VAR's variables are industrial production (IP), the consumer price index for all urban consumers (CPI), the crude materials producer price index (PPI), the federal funds rate (FFR), and the Federal Reserve's nonborrowed reserves (NBR) and adjusted total reserves (TR) series. All variables other than FFR were used in their officially deseasonalized forms and were log-transformed. ${ }^{8}$ A constant and 12 lags of each variable appear on the right-hand side of each equation. (This lag length was selected by starting with 12 lags of each variable in all equations and testing

\footnotetext{
${ }^{7}$ An early, much shorter version of the present study was Hannsgen (2008).

${ }^{8}$ The NBR variable, described below, fell to negative levels in January 2008, making the log transformation impossible. The decline began with a sharp fall in the previous month. A somewhat arbitrary decision was made to truncate the sample so as to omit the entire episode, rather than including one part of it but not another.
} 
down with an LR test. The AIC and FPE selected 3 lags. As reported in footnote 17, results from a 3-lag specification with the same data were not greatly different.)

The coefficients of the reduced form (2) and the corresponding shock vectors $\varepsilon_{\mathrm{t}}, \mathrm{t}=1$, $2,3, \ldots, \mathrm{T}$, are estimated using equation-by-equation ordinary least squares (LS). In addition to its use in many articles in the SVAR literature, two reasons could be used to justify this study's reliance on the LS estimator: 1) under a null hypothesis ${ }^{9}$ of i.i.d. normal shocks, LS is the ML estimator for the VAR, and can be combined with the ML estimator for univariate alpha-stable distributions to provide a two-step ML point estimate of the characteristic exponent of $\varepsilon_{\mathrm{it}}$, for the shock in each equation $i_{;}^{10}$ or 2 ) under a weaker null of some form of standard white-noise shocks (Lütkepohl 2006: 73-75), the LS estimates are still consistent and qualify as the efficient GLS estimates.

These considerations led to the choice of an LS estimate. This section presents a few results from the model, in order to demonstrate that they are fairly typical. Figure 2 (see back) shows IRFs with a 48-month horizon for a positive, one-standard-deviation structural shock to FFR. ${ }^{11}$ Shocks of this type are often interpreted as monetary-policy shocks. The ordering of the variables in the Cholesky decomposition was IP, CPI, PPI, FFR, NBR, TR. Monte Carlo twostandard error bands are shown in the figure. ${ }^{12}$

The IRs are mostly typical for a monetary SVAR. The response of IP (industrial production) to a contractionary FFR (federal funds rate) shock is long-lived, negative, and statistically significant. There appears to be a "price puzzle," which has been observed in many IRFs of this type (Sims 1992): CPI actually rises for a prolonged period after a positive FFR shock.

The primary empirical concern of this paper is the distribution of the innovations in the reduced-form VAR. The estimated shocks $\varepsilon_{\text {it }}^{\text {LS }}$ for each equation are plotted in figure 3 , along with dotted lines at plus and minus one standard error from the mean. Histograms appear in figure 4, with normal distributions superimposed. Some estimation results and diagnostics appear in table 1 . These should be viewed as potentially misleading because, under any alternative hypothesis involving infinite variance, unconditional moments of order greater than

\footnotetext{
${ }^{9}$ The null hypotheses referred to in this paragraph are meant to be thought of as ways of interpreting the results below, rather than as hypotheses in the formal sense of the term.

${ }^{10}$ Estimation of a 6-dimensional multivariate stable distribution is probably infeasible at this time.

${ }^{11}$ The standard deviation was adjusted for degrees of freedom.

${ }^{12}$ The error bands were calculated based on 3,000 replications in the impulse response bootstrap routine in Eviews 5.1 .
} 
2 also do not exist, and the corresponding sample moments do not converge to standard distributions.

The histograms in figures 4-9 give the impression that a non-Gaussian distribution of some type is likely. Table 1 shows that each set of residuals has excess kurtosis (with estimates ranging from 4.46 for IP to 123.60 for TR), and some are very skewed. Jarque-Bera tests for all six residuals easily reject the null of normality at a 1-percent significance level. A weaker null hypothesis of standard white-noise shocks is then preferred. Each residual tends to have weak sample autocorrelations.

Figure 3 gives the impression that the dispersion of some of the shocks changes over time. Mandelbrot (1963) observed such behavior in many financial time series, and it is certainly consistent with infinite-variance shocks. For example, deVries (1991), Haas, Mittnik, Paolella, and Steude (2005), and Liu and Brorsen (1995) present heteroskedastic models with stable, non-Gaussian shocks. On the other hand, clusters of high or low volatility are also consistent with an ARCH or generalized ARCH (GARCH) process. Such processes usually have thick-tailed unconditional distributions but finite variances (Engle 1982: 992). Therefore, a model with ARCH or GARCH shocks is another important alternative hypothesis to be used with an i.i.d., finite-variance null. Tables 2 and 3 give the results of Engle (1982) LM tests for $\mathrm{ARCH}$, first using three lags of the squared residuals in the test equation, then 12 lags. LM test statistics (third column) above the .05 critical value, which are marked with asterisks, reject the null of no (G)ARCH effects.

While the null is rejected for all six residuals for the first specification, and for four of the residuals in the second, the very small $\mathrm{R}^{2} \mathrm{~s}$ indicate that finely attuned tests are detecting fairly weak effects. Moreover, under an alternative hypothesis of stable, non-Gaussian shocks, the Engle test statistic does not admit of a clear interpretation

As discussed in section IV, many articles have investigated heteroskedasticity in monetary SVARs. Some of these break their data set into subsamples. Bernanke and Mihov (1998a: 163) find no evidence of a structural break in the policy block of their structural disturbances variance-covariance matrix in the periods 1966:1-1979:9 and 1988:4-1996:4. ${ }^{13}$ Tables 4 and 5 show the results of Engle LM tests for the first of these subperiods and for

\footnotetext{
${ }^{13}$ These subsample estimates used presample data from 1965:1 to 1965:12 and 1987:4 to 1988:3.
} 
1988:4 to the end of the sample, which were performed after re-estimating the model for the relevant subperiods. ${ }^{14}$

For the earlier subperiod, one or both of the two tests rejects the null of no (G)ARCH in the innovations in the CPI, PPI, and FFR equations. Tables 6 and 7 report that for the later subperiod, the CPI, FFR, NBR, and TR residuals appear to be free of (G)ARCH effects no matter which of the two lag lengths is used in the test equation. These findings will favor an interpretation of any statistical findings of characteristic exponents $\alpha<2$ for the homoskedastic equation-subperiod combinations as evidence of i.i.d., infinite-variance shocks rather than heteroskedastic shock processes.

\section{DO A VAR'S REDUCED-FORM SHOCKS HAVE INFINITE VARIANCES?: ESTIMATED CHARACTERISTIC EXPONENTS $\alpha$}

The Proposition in Section III establishes that we cannot orthogonalize the innovations in a standard VAR model when at least one of them has infinite variance. This section investigates the estimated shocks from the VAR described in section V above to see if they suffer from this problem. The tests below force us to limit our attention to an alternative hypothesis of one or more stable, non-Gaussian distributions, though evidence of goodness-of-fit for our estimated distributions is also presented.

Akgiray and Lamoureux (1989), Garcia, Renault, and Veredas (2006), Kogon and Williams (1998), and Lombardi and Calzolari (2008) discuss the relative merits of some methods for estimating stable parameters. According to many studies of tail-index estimators, they are often very inaccurate as estimators of alpha-stable characteristic exponents when $\alpha$ $>1.5$, at least with sample sizes of less than perhaps 10,000 (Fofack and Nolan 1999; McCulloch 1997; and Weron 2001). DuMouchel (1973) shows that except for some "exceptional parameter values," the maximum likelihood (ML) estimates of $\alpha, \beta, \gamma$, and $\delta$ are consistent and

$n^{1 / 2}(\hat{\alpha}-\alpha, \hat{\beta}-\beta, \hat{\gamma}-\gamma, \hat{\delta}-\delta)$

\footnotetext{
${ }^{14}$ Both the 1966:1-1979:9 and 1988:4-2007:11 subsample estimates marginally violated the stability VAR condition.
} 
has a limiting normal distribution with mean $(0,0,0,0)$ and covariance matrix $\mathrm{I}^{-1}$, where $\mathrm{I}$ is the Fisher information matrix, and the parameters with circumflexes are the estimates.

Here, we begin with the estimation and diagnostics approach suggested by Nolan (1999 and 2001). Three estimates of the stable parameters $\alpha, \beta, \gamma$, and $\delta$ were computed: the quantile method of McCulloch (1986), the characteristic function regression method of Koutrouvelis (1980) and Kogon and Williams (1998), and the ML estimate (DuMouchel 1973; Nolan 2001). ${ }^{15}$ Table 8 reports estimates of the characteristic exponents $(\alpha)$ for the innovations in each equation of the reduced-form VAR. ${ }^{16}$

The last column of table 8 shows the estimates, and, in parentheses, approximately 1.96 times the asymptotic standard error for the ML estimates. The results are fairly similar across estimators for each set of residuals. In all cases, the normal case $(\alpha=2)$ falls outside of a 95percent, two-sided confidence interval, implying infinite variance. Results for a three-lag specification were similar. ${ }^{1718}$

One note of caution is that for $\alpha$ close to the Gaussian value of 2 , the asymptotic normal distribution of the ML estimate of $\alpha$ is not a good approximation, with the likelihood function falling more steeply to the right of the estimate than to the left for relatively small samples (DuMouchel 1983: 1021). Also, asymptotic standard errors are not available when $\alpha=2$, due to violations of the regularity conditions required for the use of standard asymptotic distribution theory (DuMouchel 1983: 1021). Finally, these confidence intervals for $\alpha$ do not take into account discrepancies between the error terms $\varepsilon_{\mathrm{it}}$ and the corresponding least-squares residuals $\varepsilon_{\mathrm{it}}^{\mathrm{LS}}, \mathrm{i}=1,2,3,4,5,6$ and $\mathrm{t}=1,2,3, \ldots, \mathrm{T}^{19}$

The next question is whether the distributions are stable at all. Nolan notes that "As with any other family of distributions, it is not possible to prove that a given data set is stable"

\footnotetext{
${ }^{15}$ All three estimates were computed using the STABLE program, version 3.14.02, developed by John Nolan of American University and available online at academic2.american.edu/ jpnolan.

${ }^{16}$ In most cases the skew parameter $\beta$ was estimated with insufficient precision to help discriminate between the Gaussian and non-Gaussian stable cases.

${ }^{17}$ The ML estimates of the characteristic exponents for the full sample in this three-lag VAR were 1.6527, 1.7039, $1.4899,1.3992,1.6783$, and 1.7363. Alpha $=2.0000$ lay outside the 95 -percent asymptotic confidence intervals for each of the six residuals. For the 1966:1 to 1979:9 subperiod, 2.0000 was not an element of the 95-percent confidence interval in two cases, and for the 1988:4 to 2007:11 subperiod, five estimates were more than 1.96 standard errors from 2.0000 .

${ }^{18}$ Differencing all of the data or transforming the model to a VECM would not affect the characteristic exponent of a VAR error term with an alpha-stable distribution, owing to the linear properties of these distributions (Samorodnitsky and Taqqu 1994: 2).

${ }^{19}$ Bootstrapping seems complex and problematic in this case because of the thick tails and asymmetry that characterize the residual distributions, the lack of a pivotal or smooth statistic, the number of nuisance parameters, and the likely need for subsampling (Athreya 1987; Lepage and Podgórski 1996).
} 
(2001: 388). ${ }^{20}$ Nonetheless, some diagnostic tools can help determine if the data are consistent with a hypothesis of stability (Nolan 2001: 388). Figures 10-15 are variance-stabilized P-P plots $^{21}$ for the ML estimates. The closer the thick, gray line is to the thin, straight line, the better the ML stable estimate fits the data. These figures show very good fits for all six sets of innovations. $^{22} 23$

One way of testing the hypothesis that heteroskedasticity is responsible for the appearance of non-normality is to focus on estimates for subsamples. For the 1966:1-79:9 subsample, the LM tests in the previous section showed that three sets of residuals appeared to be free of (G)ARCH: IP, NBR, and TR. For the 1988:4-2007:4 subsample, the residuals for the CPI, FFR, NBR, and TR equations were homoskedastic. Tables 9 and 10 show estimates for these subperiods, with the no-ARCH equation-subperiod combinations appearing over a shaded background.

The sample splits are unevenly effective in removing the non-normality of the data.

Given the small sample sizes, the results — including the standard errors — should be interpreted with caution. The three different estimators give more divergent results for each set of residuals than in the full sample, reducing their credibility. Also, the asymptotic halfconfidence-intervals are much larger than those for the full sample.

The value 2.0000 falls within the limits of most of the ML confidence intervals for the two subperiods. Two cases in which the value $\alpha=2.0000$ falls outside the confidence interval are the shocks in the NBR and TR equations for the later subperiod, which proved to be

\footnotetext{
${ }^{20}$ Fama and Roll (1971) suggest using the informal stability-under-addition test to test for a stable distribution. This test has not performed reliably in simulation studies (Lau and Lau 1993; Fielitz and Rozelle 1983), especially with regard to robustness to mixtures.

${ }^{21}$ Variance-stabilized P-P plots for stable distributions, introduced in Michael (1983), apply an arcsin transformation to standard P-P plots in order to equalize the variance of all of the points on the plot. The resulting plot enables a better assessment of the fit at the extremes of the distribution (Nolan 2001: 388). Let $\mathrm{F}_{0}$ be the ML estimate of the distribution of one of the disturbances, using the stable model. Also, let $e_{i}, i=1,2, \ldots . ., T-1, T$ be the order statistics of the residuals. Then, the $\mathrm{i}^{\text {th }}$ abscissa of the modified P-P plot is$$
r_{i}=(2 / \pi) \arcsin \left[([i-1 / 2] / n)^{1 / 2}\right]
$$$$
\text { and the ith ordinate is }
$$$$
s_{i}=(2 / \pi) \arcsin \left\lfloor F_{0}^{1 / 2}\left(e_{i}\right)\right\rfloor
$$

The smoothed, variance-stabilized P-P plots in this paper are constructed from 200 evenly spaced points using STABLE 3.14.02.

${ }^{22}$ Among 40 other tested distributions, the one that appeared to fit the residuals most closely and consistently was a log-logistic distribution.

${ }^{23}$ Stable distributions were also fit to the data used to estimate the VAR. These fit very poorly, except for the estimated FFR distribution, which had a characteristic exponent of 1.6000, according to the ML estimate. In sharp contrast to the highly non-Gaussian shocks, most of the VAR variables had estimated alphas of 2.0000.
} 
homoskedastic in the $\mathrm{ARCH}$ tests above, with test-equation $\mathrm{R}^{2} \mathrm{~s}$ of .001. Also, for the CPI residual in the same subperiod, 2.0000 was nearly outside the 95-percent confidence interval. Combining results for both subsamples, the splits eliminate infinite variance for two shocks at most - those in the estimated IP and CPI equations. It seems that it is not possible to explain completely the thick-tailed and high-peaked shapes of the unconditional residual distributions by breaking the sample into separate homoskedastic subperiods. ${ }^{24}$ The next section discusses another approach.

\section{RESULTS WITH GARCH-FILTERED RESIDUALS}

Suppose that the shocks in equation i of the reduced form (2) were generated by the widely used $\operatorname{GARCH}(1,1)$ model

$$
\begin{aligned}
& \varepsilon_{i t}=v_{i t} \sigma_{i t} \\
& \sigma_{i t}^{2}=c+b_{0} \varepsilon_{i t}^{2}+b_{1} \sigma_{i(t-1)}^{2}
\end{aligned}
$$

where $v_{\mathrm{it}}$ is i.i.d. with zero mean and unit variance. Then, the $\varepsilon_{\mathrm{it}}$ would be leptokurtotic, even if the $v_{\text {it }}$ were normally distributed. As a matter of fact, $\operatorname{GARCH}(1,1)$ has often been used as an alternative to a alpha-stable model for thick-tailed financial data (e.g., Ghose and Kroner 1995). For each $\mathrm{i}$, a GARCH(1,1) model can be fitted to the estimated shocks $\varepsilon_{i \mathrm{it}}{ }^{\mathrm{OLS}}, \mathrm{t}=1,2$, $3, \ldots ., \mathrm{T}$, to explore this possibility. We estimate (7) using QML, which is a good estimator under a null hypothesis of $v_{\text {it }}$ with a finite fourth moment, even with a nonstationary DGP

\footnotetext{
${ }^{24}$ As a check for robustness, characteristic exponents were also estimated for 1959:1-1984:1 and 1984:2-2007:11 subperiods, since some authors find evidence that the key shift in the volatility of macro variables and/or VAR shocks in about 1984:2 (e.g., Frale and Veredas 2009; Stock and Watson 2002; Lanne and Lütkepohl 2008). For 1959:1-1984:1, the Gaussian case fell outside the 95-percent asymptotic ML confidence intervals for FFR and NBR. The latter shock was free of ARCH, at the 5 percent significance level, for both 3-lag and 12-lag testequation specifications. For 1984:2-2007:11, estimated confidence intervals for CPI, PPI, FFR, NBR, and TR excluded $\alpha=2.0000$. Again, the shock to the equation for NBR was homoskedastic, according to the two ARCH LM tests, at the 5 percent significance level. (Unfortunately, one inverse characteristic root for the 1959:1 to 1984: 1 subsample had modulus of slightly greater than 1, while the estimated VAR for the 1984:2 to 2007:11 subsample satisfied the stability condition.)
} 
(Jensen and Rahbek 2004; Lee and Hansen 1994; Lumsdaine 1996). ${ }^{25}$ The results are shown in table 11. For the residuals in the equations for PPI and FFR

$$
\hat{b}_{0}+\hat{b}_{1} \approx 1
$$

suggesting an IGARCH model, while that sum is much greater than 1 for the NBR and TR processes, implying explosive variance processes (7). Hence, four of the shocks may well be non-covariance stationary and have infinite unconditional variance if only for that reason. On the other hand, the estimated $b_{0}$ is within one Bollerslev-Wooldridge (1992) standard error of the covariance-stationary region of the parameter space for the NBR and TR shocks, and the PPI and FFR estimates fall just within that region, given the estimate of $b_{1}$. For all equations, the $v_{\text {it }}$ also appear to have infinite variances, as seen in table 12. All of the 95-percent ML confidence intervals for these filtered shocks exclude the Gaussian case, with all estimated alphas lying between 1.7638 and 1.8897. LM tests on each series of filtered residuals fail to reject a no-ARCH null at even a .20 significance level, indicating that the filters worked well to provide a signal of the conditional distributions of the error terms. (This was true for both 3-lag and 12-lag specifications of the test equation.) Variance-stabilized P-P plots for the ML estimates show alpha-stable fits that are roughly as good as those shown in figures 10 to 15 for the unfiltered residuals. Perhaps a good model for all of the residuals might be a GARCH or similar heteroskedastic process with stable, non-Gaussian shocks - and hence infinite unconditional variances — rather than a more conventional heteroskedastic model or a homoskedastic model with structural breaks.

\section{SUMMARY AND CONCLUSIONS}

This paper reports estimates of the characteristic exponents $\alpha$ of the innovations $\varepsilon_{i t}{ }_{\text {LS }}^{\text {in a six- }}$ variable monetary VAR. The reason for seeking these estimates is that for $\alpha<2$, alpha-stable distributions have infinite variances, making it impossible to transform the reduced-form DGP

\footnotetext{
${ }^{25}$ Linton, Pan, and Wang (2010) study the properties of the QML estimator for GARCH(1,1) when $v_{\text {it }}$ is in the domain of attraction of a stable variate with $1<\alpha<2$. Like Hall and Yao (2003) and Huang, Wang, and Yao (2008), they consider GARCH estimators and confidence intervals that are specially designed to be robust to thick tails. Berkes, Horváth, and Kokoszka (2003) and Mikosch and Straumann (2006) also prove important properties of the QML estimator for GARCH processes with heavy-tailed shocks.
} 
into a set of structural equations with orthogonal structural shocks. Proposition 1 shows that no method of finding orthogonal disturbances can work when at least one innovation has infinite variance, because no nonsingular transformation of the innovations yields orthogonal disturbances.

This paper's VAR appears to lead to impulse response functions that are typical in the monetary VAR literature. However, diagnostics show that the innovations have thick-tailed and skewed distributions, with Jarque-Bera tests rejecting the null of normality at a .01 significance level in each equation. On the other hand, Engle (1982) LM tests indicate fairly weak (G)ARCH effects. Such heteroskedastic processes tend to have thick-tailed distributions. Pursuing instead a hypothesis that the innovations have stable, non-Gaussian unconditional distributions, the paper finds ML estimates of the $\alpha$ 's ranging from 1.5504 for the innovations in the equation for the crude materials producer price index (PPI) to 1.7734 for the industrial production (IP) equation. Asymptotic confidence intervals for all of the ML estimates rule out $\alpha=2$, the value for the Gaussian case, though these intervals do not take into account uncertainty due to random differences between the error terms and the LS residuals. P-P plots provide visual confirmation that the estimated stable distributions fit the innovations very well.

While the main concern of this paper is the unconditional moments in the covariance matrix V of the reduced-form shocks, the study also attempted to separate the respective influences of time-varying dispersion and thick-tailed shocks, in light of recent VAR studies emphasizing heteroskedasticity. The study re-estimates the VAR for subperiods that appear free of heteroskedasticity based on Engle LM tests. For the 1988:4-2007:11 subsample, two variables without statistically significant (G)ARCH effects - the innovations in the NBR and TR equations - had estimated $\alpha$ 's that were very close to the estimates for the full sample.

Another attempt to investigate time-varying variance involved estimating $\operatorname{GARCH}(1,1)$ models by Gaussian QML and fitting alpha-stable distributions to the standardized residuals. The Engle ARCH tests for the latter shocks failed to reject the null of no-(G)ARCH in all cases. The ML estimates of $\alpha$ for the filtered shocks were somewhat higher, probably reflecting the reduction or elimination of heteroskedasticity, but all of the estimated confidence intervals still implied infinite-variance at a 95-percent confidence level. P-P plots suggested that the estimated alpha-stable distributions still fit the shocks closely. Two of the estimated GARCH processes were non-covariance stationary, and two more were marginally covariancestationary, but very close to IGARCH. However, many of the estimated coefficients of the 
variance processes had very large robust standard errors, making inference about covariancestationarity impossible.

The work by Hill (2006) cited in section IV above on nonlinear projections and impulse response functions and other, similar efforts may offer some hope for an alternative approach when standard SVAR analysis is precluded by problems with infinite-variance. The evidence in this paper suggests that a better model than SVAR for some macro data might combine time-varying dispersion with stable, non-Gaussian shocks. The empirical generality of the findings presented here is not yet known. Hence, caution seems warranted in the use of SVAR. 


\section{REFERENCES}

Akgiray, V., and C. Lamoureux. 1989. "Estimation of Stable Parameters: A Comparative Study." Journal of Business and Economic Statistics 7(1): 85-93.

Andrews, B., M. Calder, and R.A. Davis. 2009. "Maximum Likelihood Estimation for AlphaStable Autoregressive Processes." Annals of Statistics 37(4): 1946-1982.

Athreya, K.B. 1987. "Bootstrap of the Mean in the Infinite Variance Case." Annals of Statistics 15(2): 724-731.

Bartels, R. 1977. "On the Use of Limit Theorem Arguments in Economic Statistics." The American Statistician 31(2): 85-87.

Berkes, I., L. Horváth, and P. Kokoszka. 2003. "GARCH Processes: Structure and Estimation.” Bernoulli 9(2): 201-227.

Bernanke, B. 1986. "Alternative Explanations of the Money-Income Correlation." CarnegieRochester Conference Series on Public Policy 25(1) 49-99.

Bernanke, B., and I. Mihov. 1998a. "The Liquidity Effect and Long-run Neutrality." CarnegieRochester Conference Series on Public Policy 49(1): 149-194.

_ 1998b. "Measuring Monetary Policy.” Quarterly Journal of Economics 113(3): 869902.

Bhansali, R.J. 1993. "Estimation of the Impulse Response Coefficients of a Linear Process with Infinite Variance." Journal of Multivariate Analysis 45(1): 274-290.

Blanchard, O., and D. Quah. 1989. "The Dynamic Effects of Aggregate Demand and Supply Disturbances." American Economic Review 79(3): 655-673.

Blanchard, O., and M. Watson. 1986. "Are Business Cycles All Alike?” In R. J. Gordon, ed., The American Business Cycle: Continuity and Change. Chicago: University of Chicago Press.

Blattberg, R., and N. Gonedes. 1974. "A Comparison of the Stable and Student Distributions as Statistical Models for Stock Prices." Journal of Business 47(2): 244-280.

Bollerslev, T., and J. Wooldridge. 1992. "Quasi-Maximum Likelihood Estimation and Inference in Dynamic Models with Time-Varying Covariances." Econometric Reviews 11(2): 143-172.

Christiano, L.J., M. Eichenbaum, and C. Evans. 1996. "The Effects of Monetary Policy Shocks: Evidence from the Flow of Funds." Review of Economics and Statistics 78(1): $16-34$. 
. 1999. "Monetary Policy Shocks: What Have We Learned and to What End?" in J. B. Taylor and M. Woodford (eds.), Handbook of Macroeconomics, Vol. 1A. New York: Elsevier.

Clark, P.K. 1973. "A Subordinated Process Model with Finite Variance for Speculative Prices." Econometrica 41(1): 135-155.

Cline, D.B.H. 1989. "Consistency for Least Squares Regression Estimators with Infinite Variance Data.” Journal of Statistical Planning and Inference 23(2): 163-179.

Cogley, T., and T.J. Sargent. 2005. "Drifts and Volatilities: Monetary Policies and Outcomes in the Post-WWII US.” Review of Economic Dynamics 8(2): 262-302.

DasGupta, M., and S.K. Mishra. 2004. "Least Absolute Deviation Estimation of Linear Econometric Models: A Literature Review." Unpublished Manuscript. India: North Eastern Hill University.

Davidson, R., and J.G. MacKinnon. 2004. Econometric Theory and Methods. New York: Oxford University Press.

deVries, C.G. 1991. "On the Relation between GARCH and Stable Processes." Journal of Econometrics 48(3): 313-24.

DuMouchel, W. H. 1973. "On the Asymptotic Normality of the Maximum-Likelihood Estimate When Sampling from a Stable Distribution." Annals of Statistics 1(5): 948957.

. 1983. "Estimating the Stable Index Alpha in Order to Measure Tail Thickness: A Critique." Annals of Statistics 11(4): 1019-1031.

Engle, R. F. 1982. “Autoregressive Conditional Heteroskedasticity with Estimates of the Variance of United Kingdom Inflation.” Econometrica 50(4): 987-1007.

Fama, E. 1963. "Mandelbrot and the Stable Paretian Hypothesis." Journal of Business 36(4): $420-429$.

1965a. "Portfolio Analysis in a Stable Paretian Market." Management Science 11(3A): 404-419.

—. 1965b. “The Behavior of Stock Market Prices.” Journal of Business 38(1): 34-105.

Fama, E., and R. Roll. 1971. "Parameter Estimates for Symmetric Stable Distributions." Journal of the American Statistical Association 66(334): 331-338.

Fielitz, B., and J. Rozelle. 1983. "Stable Distributions and Mixtures of Distributions Hypothesis for Common Stock Returns." Journal of the American Statistical Association 78(381): 28-36. 
Feller, W. 1971. An Introduction to Probability Theory and Its Applications, Vol. II. New York: Wiley.

Fofack, H., and J.P. Nolan. 1999. "Tail Behavior, Modes and Other Characteristics of Stable Distributions." Extremes 2(1): 1-19.

Frale, C., and D. Veredas. 2009. "A Monthly Volatility Index for the U.S. Real Economy." Working Paper. University of Tor Vergata and Université Libre de Bruxelles.

Galí, J. 1999. "Technology, Employment, and the Business Cycle: Do Technology Shocks Explain Aggregate Fluctuations?” American Economic Review 89(1): 249-271.

Gallant, R., P. Rossi, and G. Tauchen. 1993. "Nonlinear Dynamic Structures.” Econometrica 61(4): 871-907.

Gambetti, L., E. Pappa, and F. Canova. 2008. "The Structural Dynamics of U.S. Output and Inflation: What Explains the Changes?" Journal of Money, Credit, and Banking 40(23): $369-388$.

Garcia, R., E. Renault, and D. Veredas. 2006. "Estimation of Stable Parameters by Indirect Inference.” Working Paper. Montréal: Université de Montréal.

Ghose, D., and K.F. Kroner. 1995. "The Relationship between GARCH and Symmetric Stable Processes: Finding the Source of Fat Tails in Financial Data." Journal of Empirical Finance 2(3): 225-251.

Granger, C.W.J., and D. Orr. 1972. “'Infinite Variance' and Research Strategy in Time Series Analysis." Journal of the American Statistical Association 67(338): 275-285.

Haas, M., S. Mittnik, M.S. Paolella, and S.C. Steude. 2005. "Stable Mixture GARCH Models." Swiss National Science Foundation FINRISK Working Paper No. 257.

Hall, P., and Q. Yao. 2003. "Inference in ARCH and GARCH Models with Heavy-Tailed Errors." Econometrica 71(1): 285-317.

Hamilton, J.D. 1994. Time Series Analysis. Princeton, NJ: Princeton University Press.

Hannan, E.J., and M. Kanter. 1977. "Autoregressive Processes with Infinite Variance.” Journal of Applied Probability 14(2): 411-415.

Hannsgen, G. 2008. "Do the Innovations in a Monetary VAR Have Finite Variances?" Working Paper No. 546. Annandale-on-Hudson, NY: The Levy Economics Institute.

Hill, J.B. 2006. "Strong Orthogonal Decompositions and Non-Linear Impulse Response Functions for Infinite-Variance Processes." The Canadian Journal of Statistics 34(3): 453-473. 
Huang, D., H. Wang, and Q. Yao. 2008. "Estimating GARCH Models: When to Use What?" Econometrics Journal 11(1): 27-38.

Jensen, S., and A. Rahbek. 2004. "Asymptotic Inference for Nonstationary GARCH.” Econometric Theory 20(6): 1203-1226.

Kanter, M., and W.L. Steiger. 1974. "Regression and Autoregression with Infinite Variance." Advances in Applied Probability 6(4): 768-783.

Kogon, S.M. and D.B. Williams. 1998. "Characteristic Function Based Estimation of Stable Parameters.” in R. Adler, R. Feldman, and M. Taqqu (eds.), A Practical Guide to Heavy Tails. Boston: Birkhauser.

Koop, G., M.H. Pesaran, and S. Potter. 1996. "Impulse Response Analysis in Nonlinear Multivariate Models.” Journal of Econometrics 4(1): 119-147.

Koutrouvelis, I.A. 1980. "Regression-Type Estimation of the Parameters of Stable Laws." Journal of the American Statistical Association 75(372): 918-928.

Lanne, M., and H. Lütkepohl. 2008. "Identifying Monetary Policy Shocks via Changes in Volatility." Journal of Money, Credit, and Banking 40(6): 1131-1149.

- 2010. "Structural Vector Autoregression with Nonnormal Residuals." Journal of Business and Economic Statistics 28(1): 159-168.

Lau, H.-S., and Amy H.-L. Lau. 1993. "The Reliability of the Stability-under-Addition Test for the Stable-Paretian Hypothesis.” Journal of Statistical Computation and Simulation 48(1): 67-80.

Lee, S.-W, and B.E. Hanson. 1994. "Aymptotic Behavior for the GARCH(1,1) QuasiMaximum Likelihood Estimator.” Econometric Theory 10(1): 29-52.

Leeper, E.M., C.A. Sims, and T. Zha. 1996. "What Does Monetary Policy Do?” Brookings Papers on Economic Activity 2(1): 1-78.

Lepage, R., and K. Podgórski. 1996. "Resampling Permutations in Regression without Second Moments." Journal of Multivariate Analysis 57(1): 119-141.

Linton, O., J. Pan, and H. Wang. 2010. "Estimation for a Nonstationary Semi-Strong GARCH(1,1) Model with Heavy-Tailed Errors.” Econometric Theory 26(1): 1-28.

Liu, S.-M., and B. W. Brorsen. 1995. "Maximum Likelihood Estimation of a GARCH-Stable Model." Journal of Applied Econometrics 10(3): 273-285.

Lombardi, M., and G. Calzolari. 2008. "Indirect Estimation of Alpha-Stable Distributions and Processes.” Econometrics Journal 11(1): 193-208. 
Lumsdaine, R.L. 1996. "Consistency and Asymptotic Normality of the Quasi-Maximum Likelihood Estimator in $\operatorname{IGARCH}(1,1)$ and Covariance Stationary GARCH( $(1,1)$ Models." Econometrica 64(2):575-596.

Lütkepohl, H. 2006. New Introduction to Multiple Time Series Analysis. New York: Springer.

Mandelbrot, B. 1963. "The Variation of Certain Speculative Prices.” Journal of Business 36(3): 394-419.

. 1967. "The Variation of Some Other Speculative Prices." Journal of Business 40(4): 393-413.

McCulloch, J.H. 1986. "Simple Consistent Estimators of Stable Distribution Parameters." Communications in Statistics-Simulation and Computation 15(4): 1109-1136.

- 1997. "Measuring Tail Thickness to Estimate the Stable Index $\alpha$ : A Critique." Journal of Business and Economic Statistics 15(1): 74-81.

Michael, J.R. 1983. “The Stabilized Probability Plot.” Biometrika 70(1): 11-17.

Mikosch, T., and D. Straumann. 2006. "Stable Limits of Martingale Transforms with Application to the Estimation of GARCH Parameters." The Annals of Statistics 34(1): 493-522.

Mirowski, P. 1990. "From Mandelbrot to Chaos in Economic Theory." Southern Economic Journal 57(2): 289-307.

Nolan, J. 1999. "Fitting Data and Assessing Goodness of Fit with Stable Distributions." Unpublished Manuscript. Washington, DC: American University.

- 2001. "Maximum Likelihood Estimation of Stable Parameters." In O. BarndorffNielsen, T. Mikosch, and S. Resnick, eds., Lévy Processes: Theory and Application. Boston: Birkhauser.

- Forthcoming. Stable Distributions: Models for Heavy-Tailed Data. Boston: Birkhauser.

Primiceri, G. 2005. "Time Varying Structural Vector Autoregressions and Monetary Policy." Review of Economic Studies 72(3): 821-852.

Rachev, S.T., J.-R. Kim, and S. Mittnik. 1997. "Econometric Modeling in the Presence of Heavy-Tailed Innovations: A Survey of Some Recent Advances." Stochastic Models 13(4): 841-866.

Samorodnitsky, G., and M.S. Taqqu. 1994. Stable Non-Gaussian Random Processes: Stochastic Models with Infinite Variance. New York: Chapman and Hall. 
Shapiro, M.D., and M.W. Watson. 1989. "Sources of Business Cycle Fluctuations.” Working Paper No. 2589. Cambridge, MA: National Bureau of Economic Research.

Sims, C. 1980. "Macroeconomics and Reality." Econometrica 48(1): 1-48.

. 1986. “Are Forecasting Models Usable for Policy Analysis?” Federal Reserve Bank of Minneapolis Quarterly Review 10(1): 1-16.

. 1992. "Interpreting the Macroeconomic Time Series Facts: The Effects of Monetary Policy." European Economic Review 36(5): 975-1000.

Sims, C., D.F. Waggoner, and T. Zha. 2008. "Methods for Inference in Large MultipleEquation Markov-Switching Models.” Journal of Econometrics 146(2): 255-274.

Sims, C., and T. Zha. 2006. "Were There Regime Switches in Monetary Policy?" American Economic Review 96(1) 54-81.

Stock, J.H., and M.W. Watson. 2002. "Has the Business Cycle Changed and Why?" NBER Macroeconomics Annual 17: 159-218.

Strongin, S. 1995. "The Identification of Monetary Policy Disturbances: Explaining the Liquidity Puzzle.” Journal of Monetary Economics 35(3): 463-497.

Watson, M.W. 1994. "Vector Autoregression and Cointegration.” In R. F. Engle and D. L. McFadden, eds., Handbook of Econometrics, Vol. IV. New York: Elsevier.

Weron, R. 2001. "Lévy-Stable Distributions Revisited: Tail Index > 2 Does Not Exclude the Lévy-Stable Regime.” International Journal of Modern Physics C 12(2): 209-223.

Yohai, V.J., and R.A. Maronna. 1977. "Asymptotic Behavior of Least Squares Estimates for Autoregressive Processes with Infinite Variances." Annals of Statistics 5(3): 554-560.

Zarepour, M., and S.M. Roknossadati. 2008. "Multivariate Autoregression of Order One with Infinite Variance Innovations.” Econometric Theory 24(3) 677-695. 
Figure 1. Densities of Standard Normal Distribution and Symmetric Stable with Alpha $=1.7$

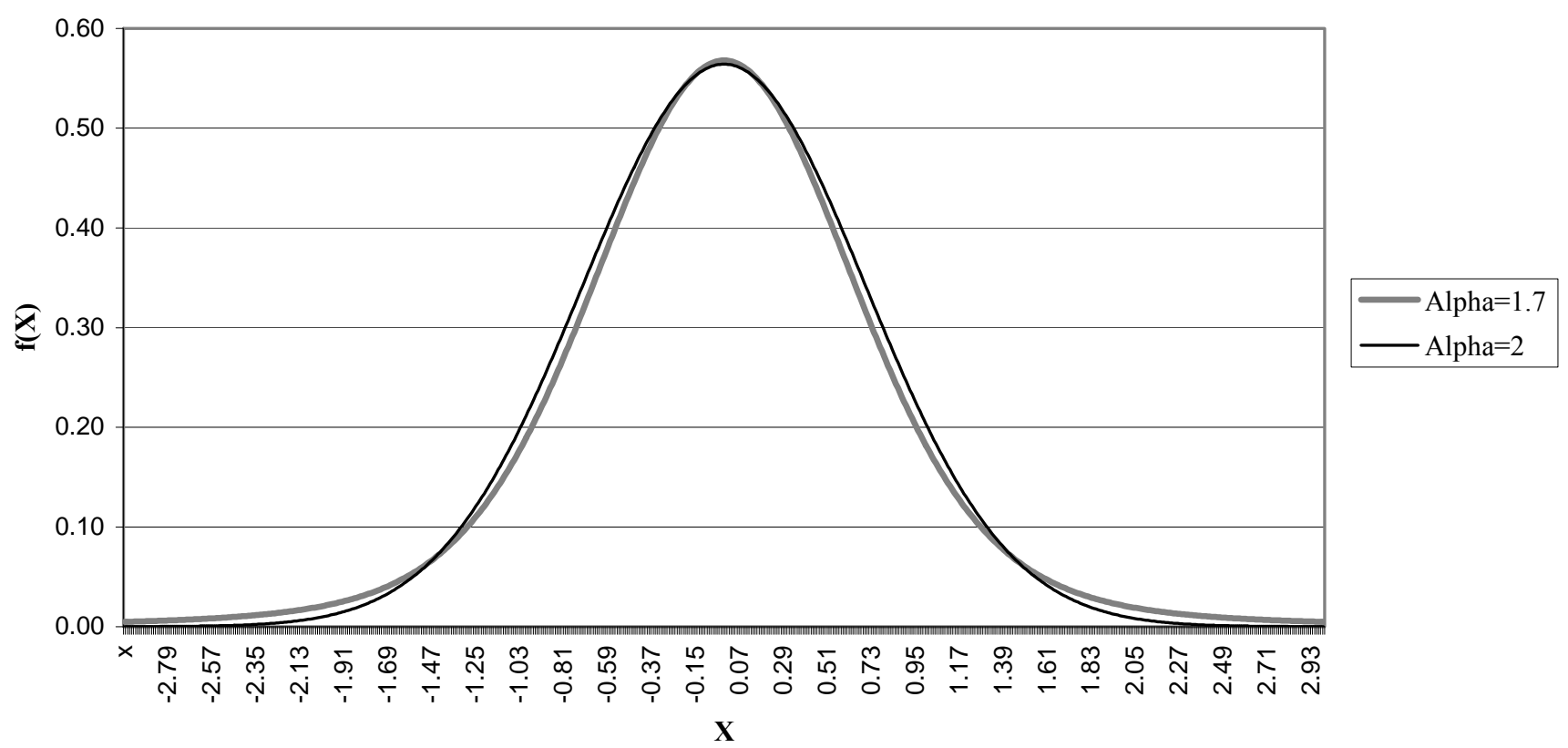


Figure 2. Response to Cholesky One-S.D. Shocks in FFR \pm 2 S.E.

Response to Cholesky One S.D. Innovations \pm 2 S.E.
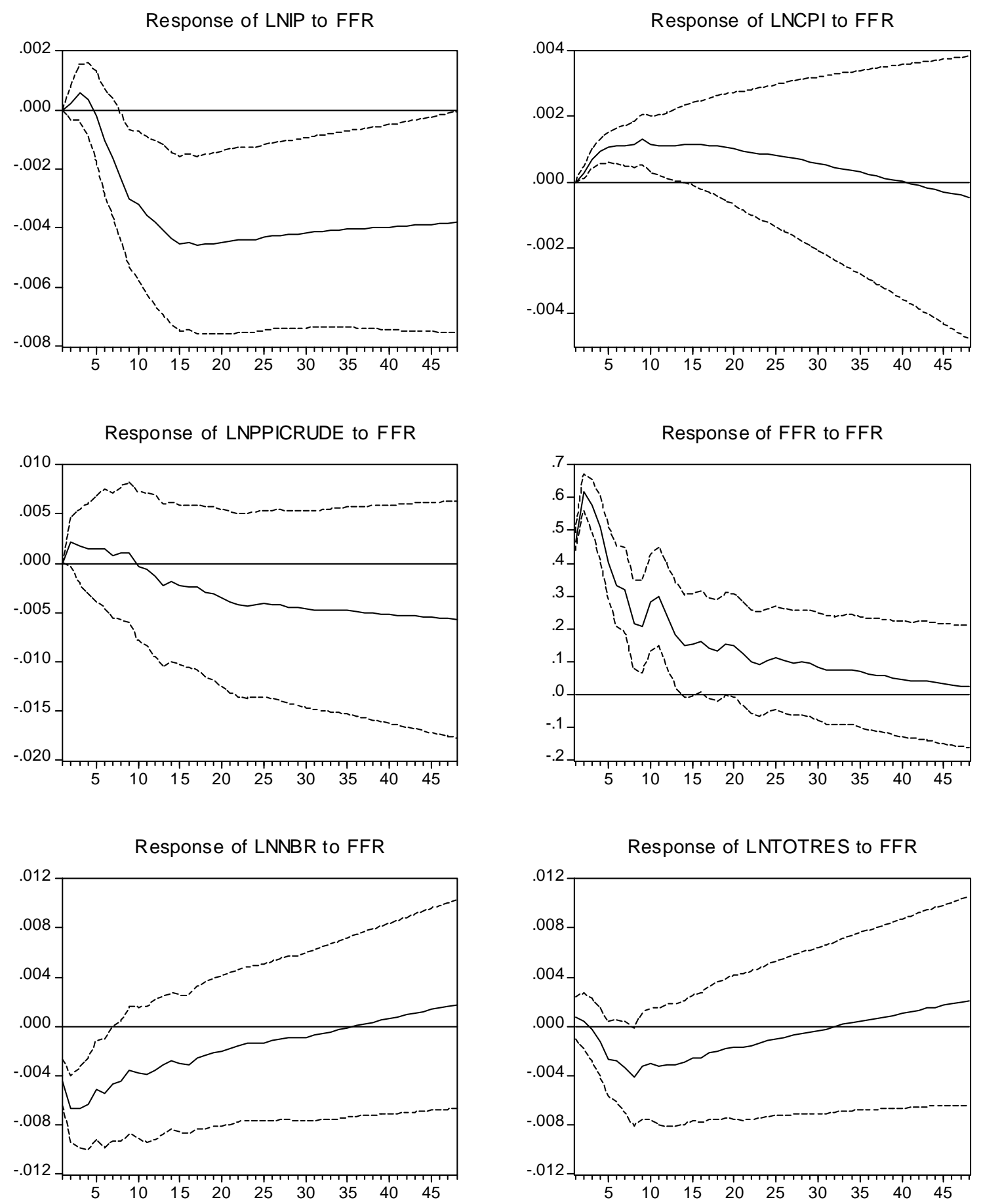
Figure 3. Reduced-Form VAR Least-Squares Residuals (Shocks) $\varepsilon_{t}^{\text {LS }}$

LNIP Residuals
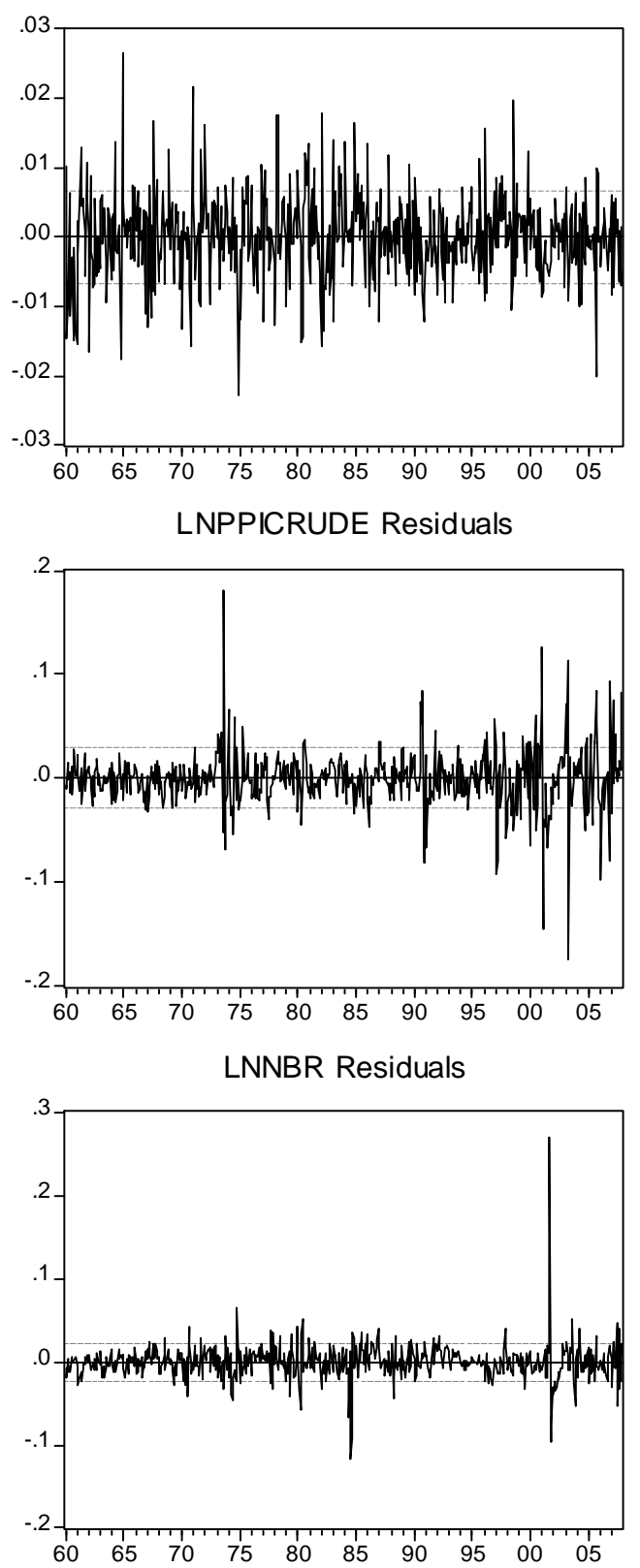

LNCPI Residuals
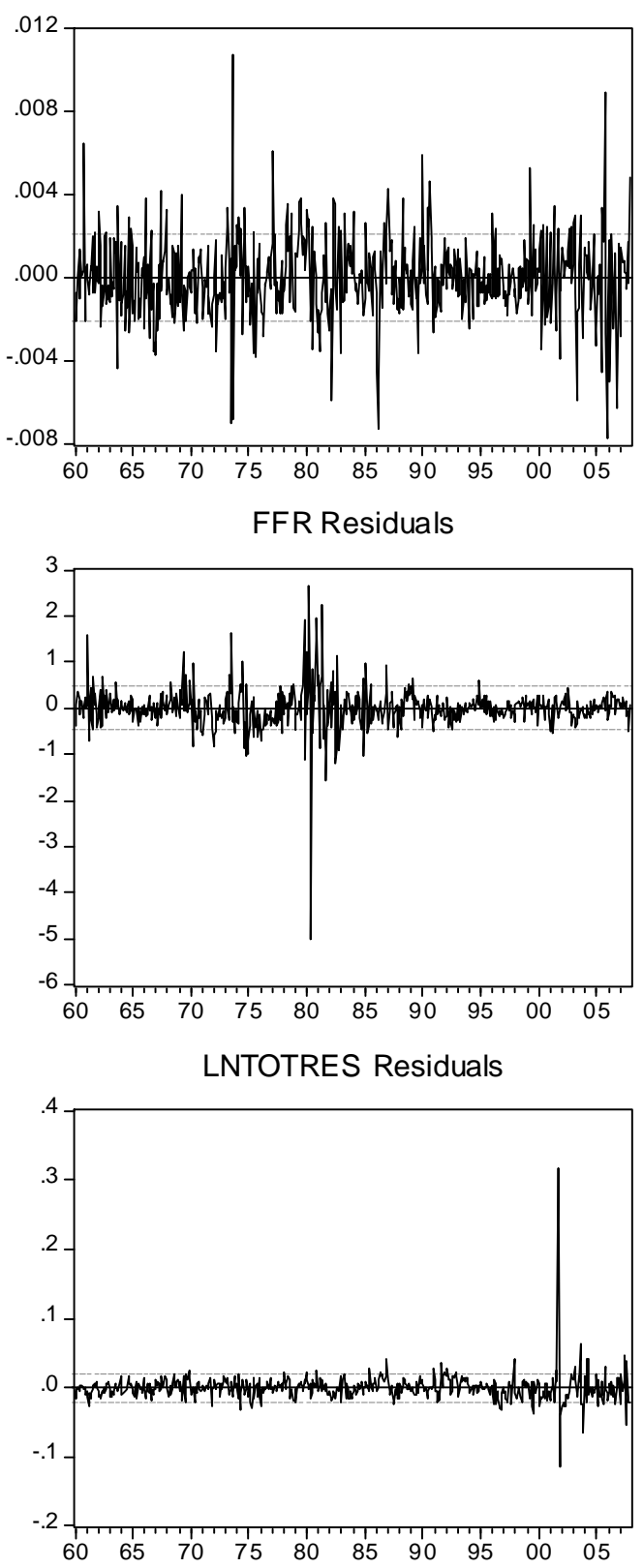
Figures 4-9. Histograms for $\boldsymbol{\varepsilon}_{\mathbf{t}}^{\text {LS }}$; INNOV1= IP equation; $2=$ CPI equation; $3=$ PPI equation; $4=$ FFR equation; $5=$ NBR equation; $6=$ TR equation

\section{Histogram and Normal curve for variable INNOV1}

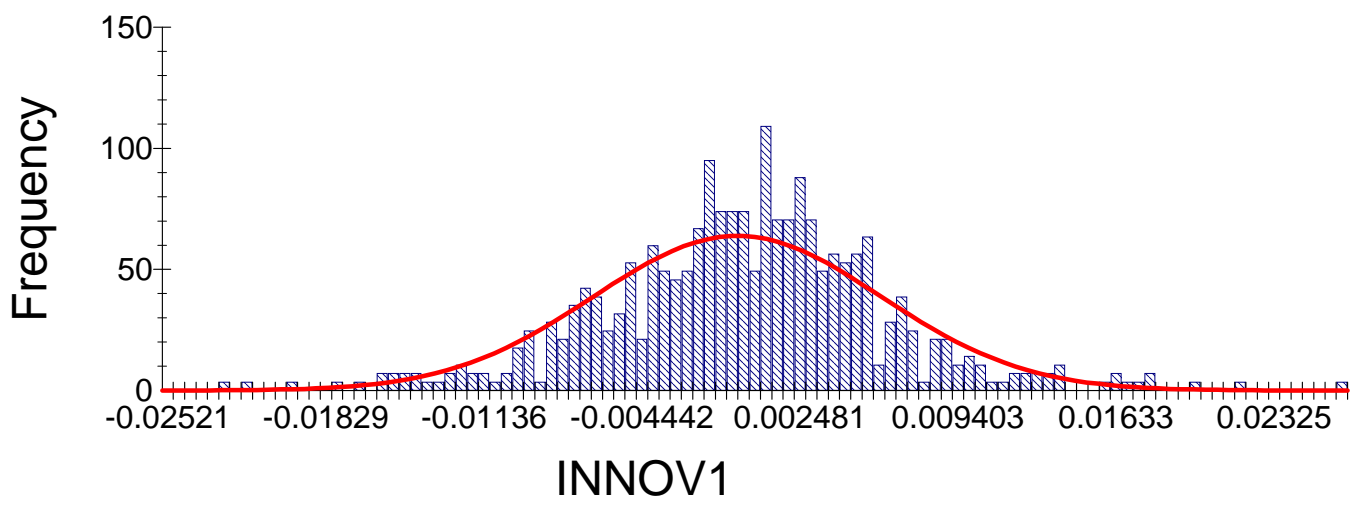

\section{Histogram and Normal curve for variable INNOV2}

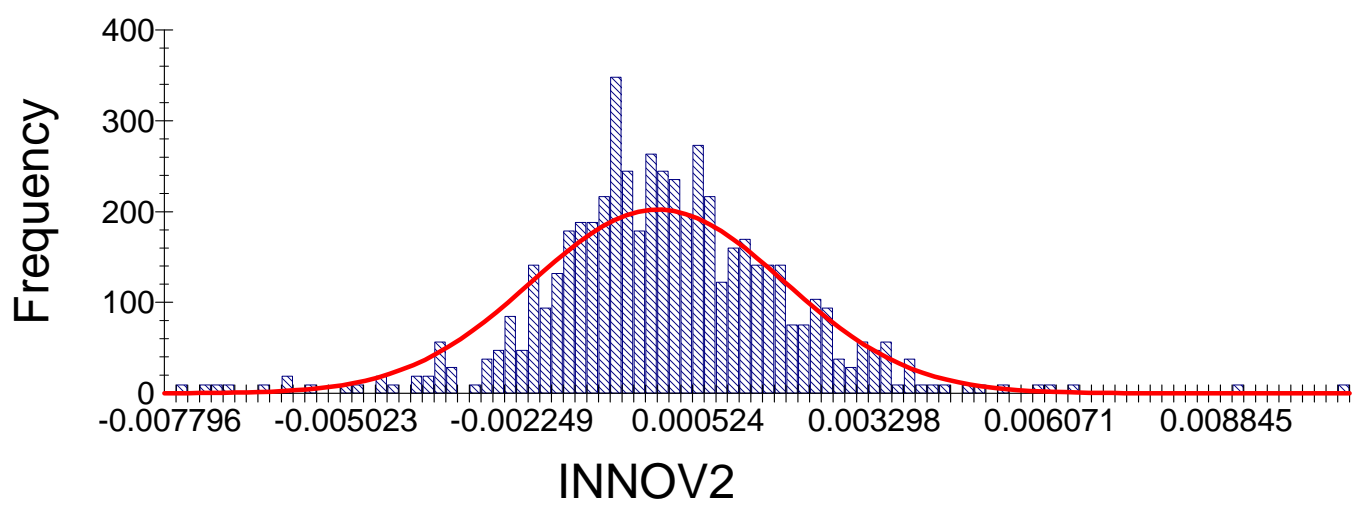




\section{Histogram and Normal curve for variable INNOV3}

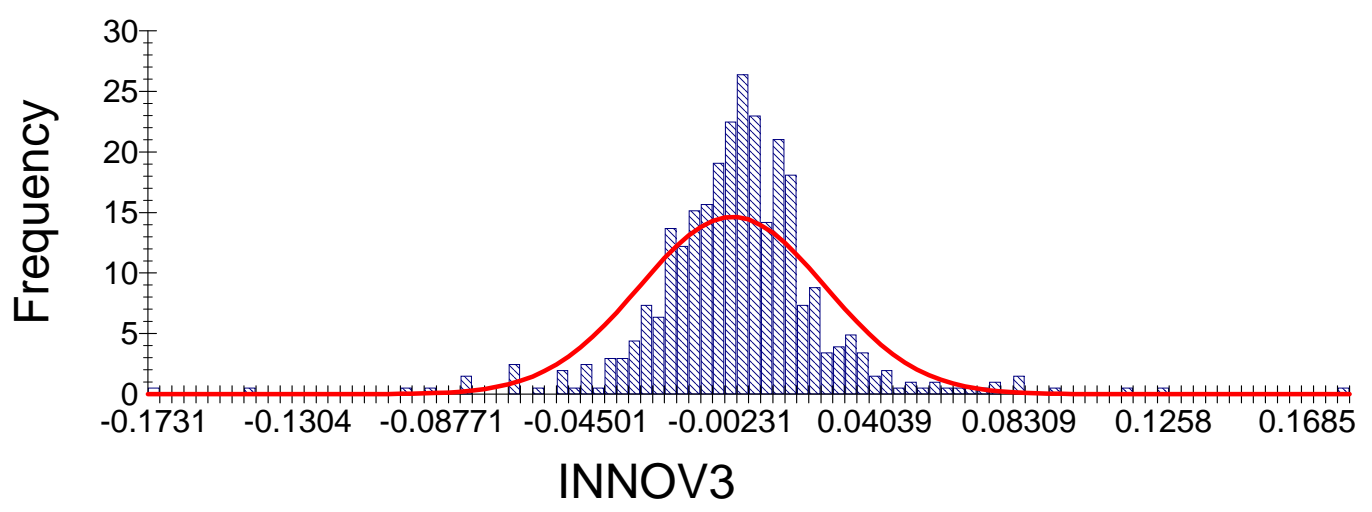

Histogram and Normal curve for variable INNOV4

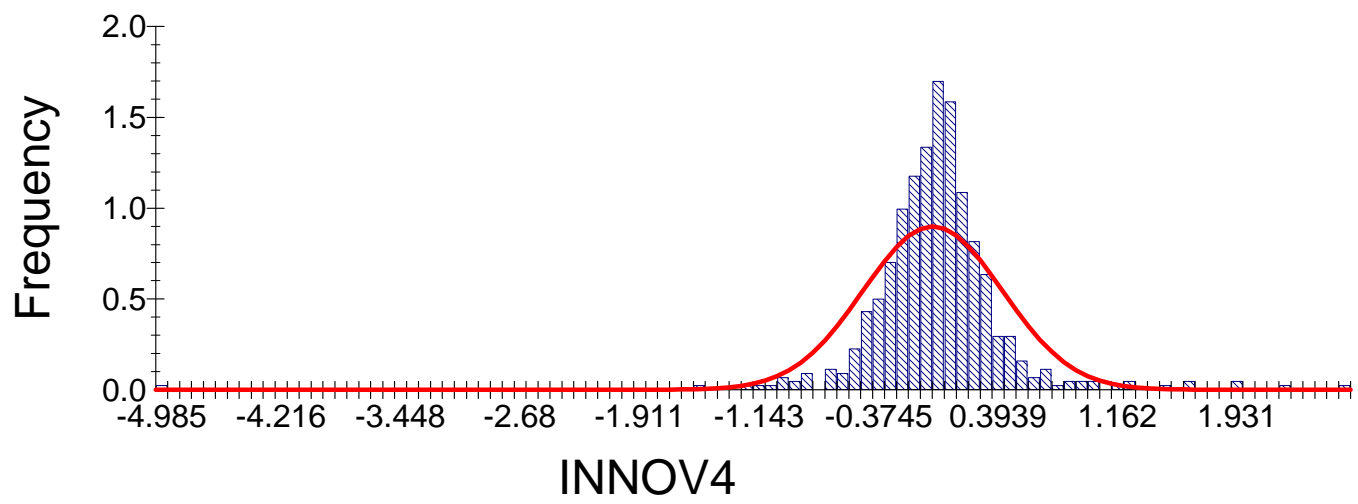

Histogram and Normal curve for variable INNOV5

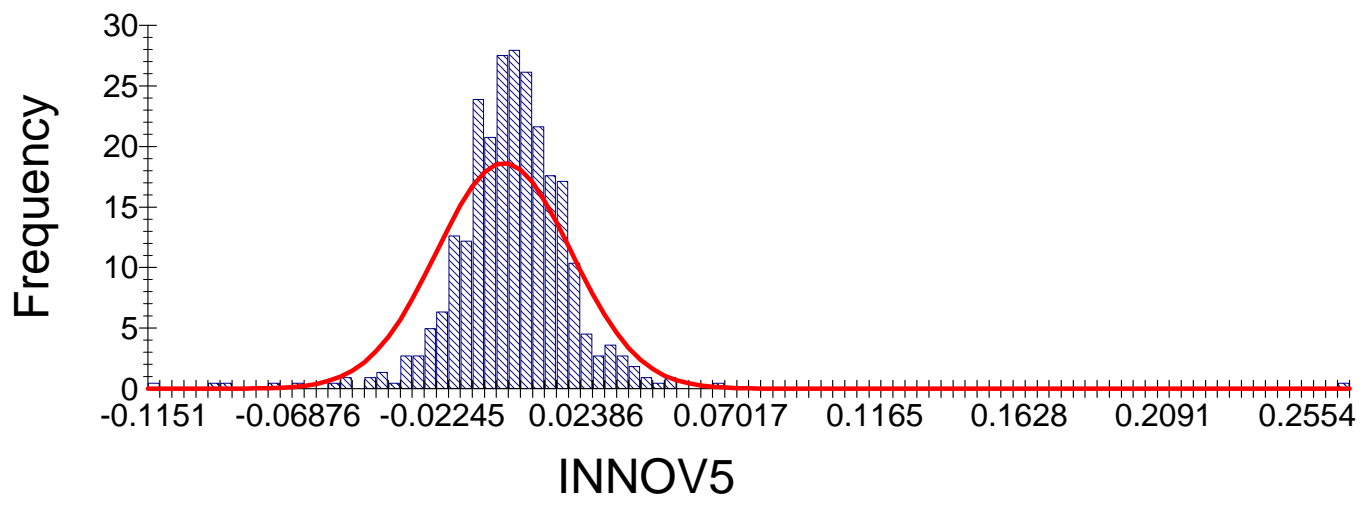




\section{Histogram and Normal curve for variable INNOV6}

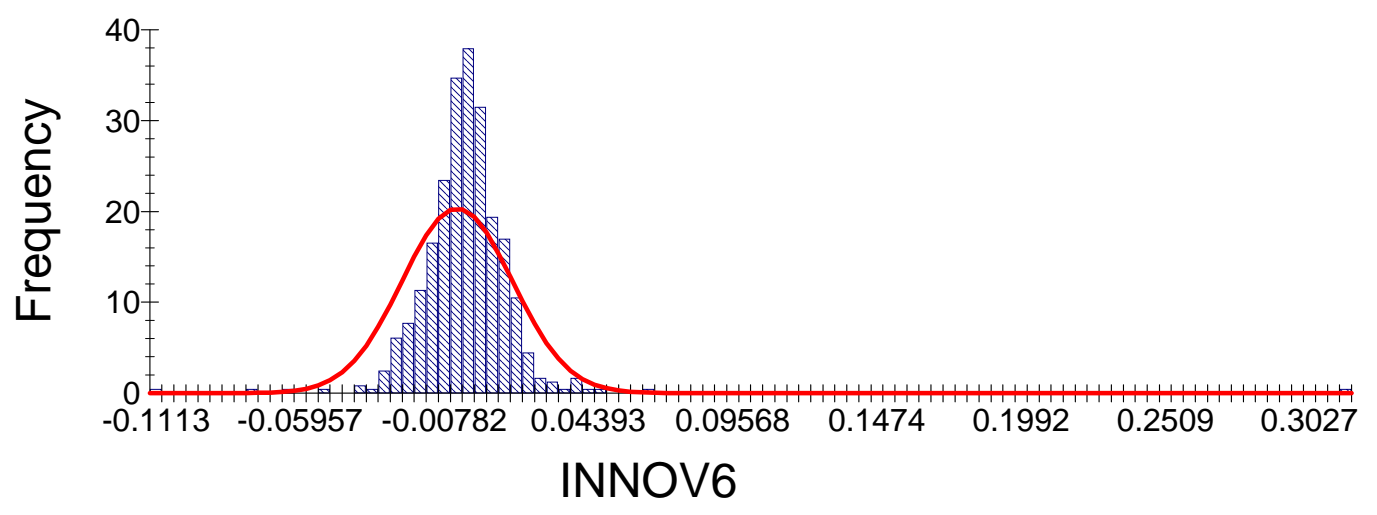


Figure 10. Variance-Stabilized P-P Plot for Innovation in IP Equation: AlphaStable Fit (ML Estimate)

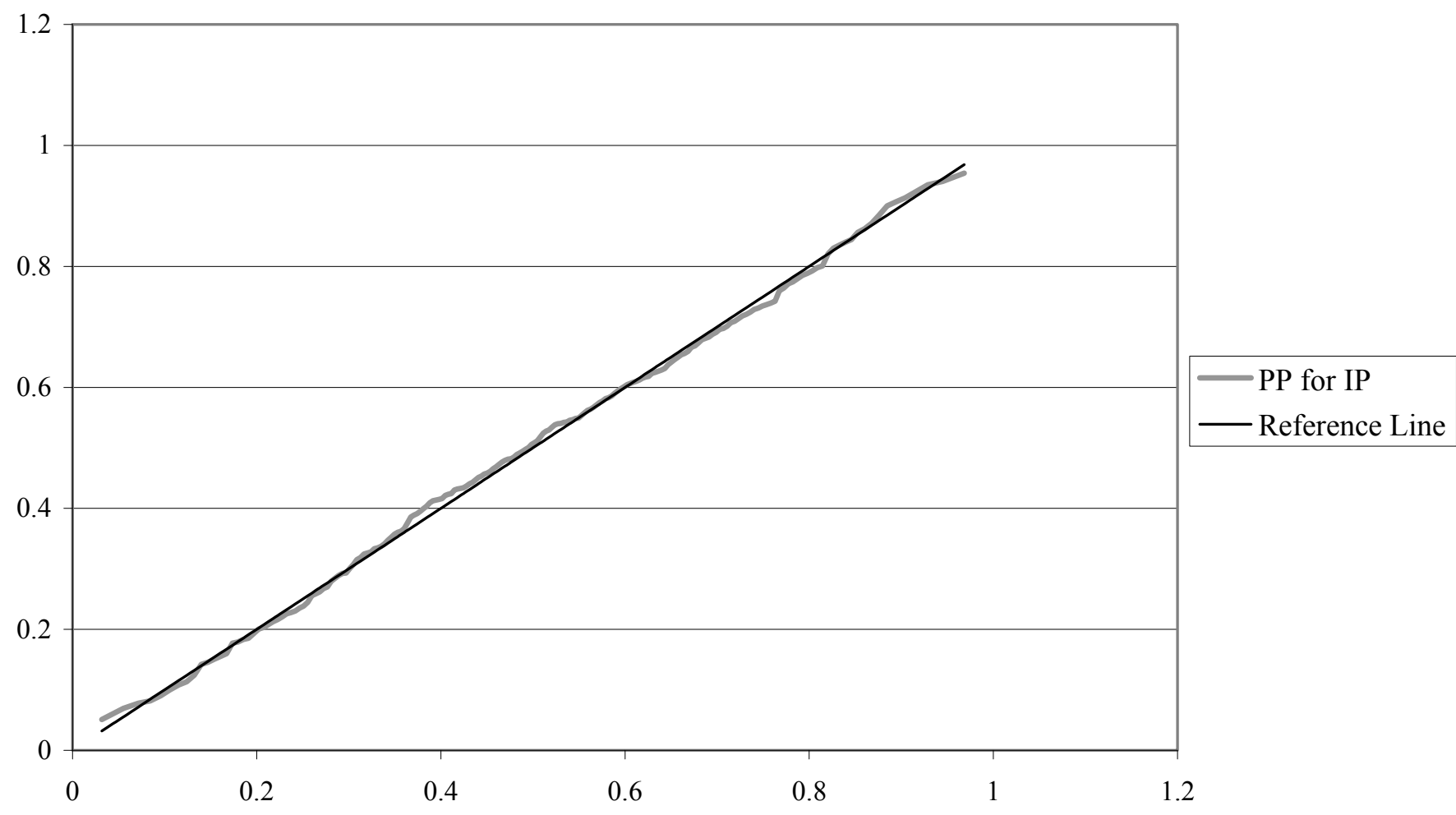


Figure 11. Variance-Stabilized PP Plot for Innovation in CPI Equation: AlphaStable Fit (ML Estimate)

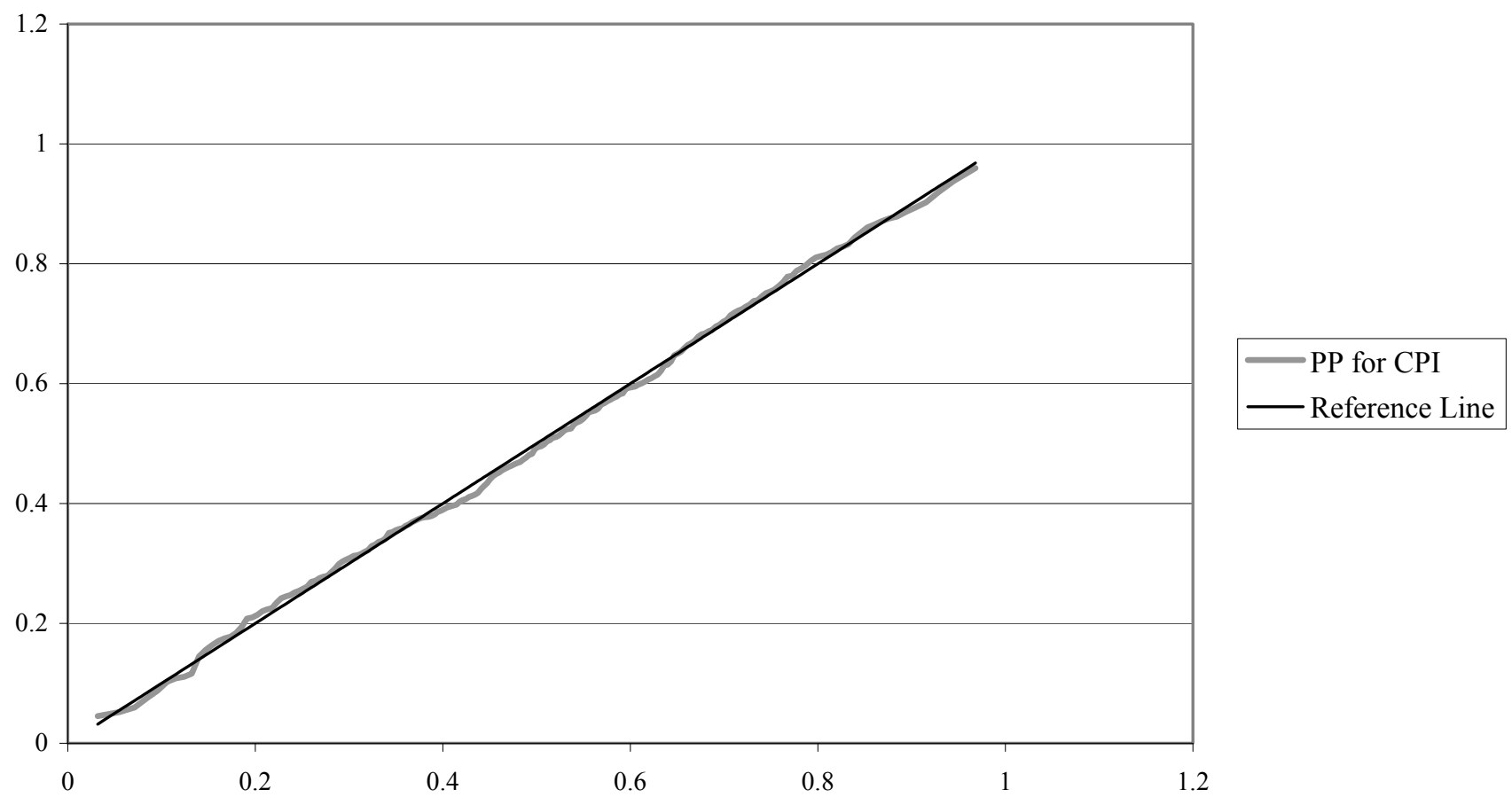


Figure 12. Variance-Stabilized PP Plot for Innovation in PPI Equation: AlphaStable Fit (ML Estimate)

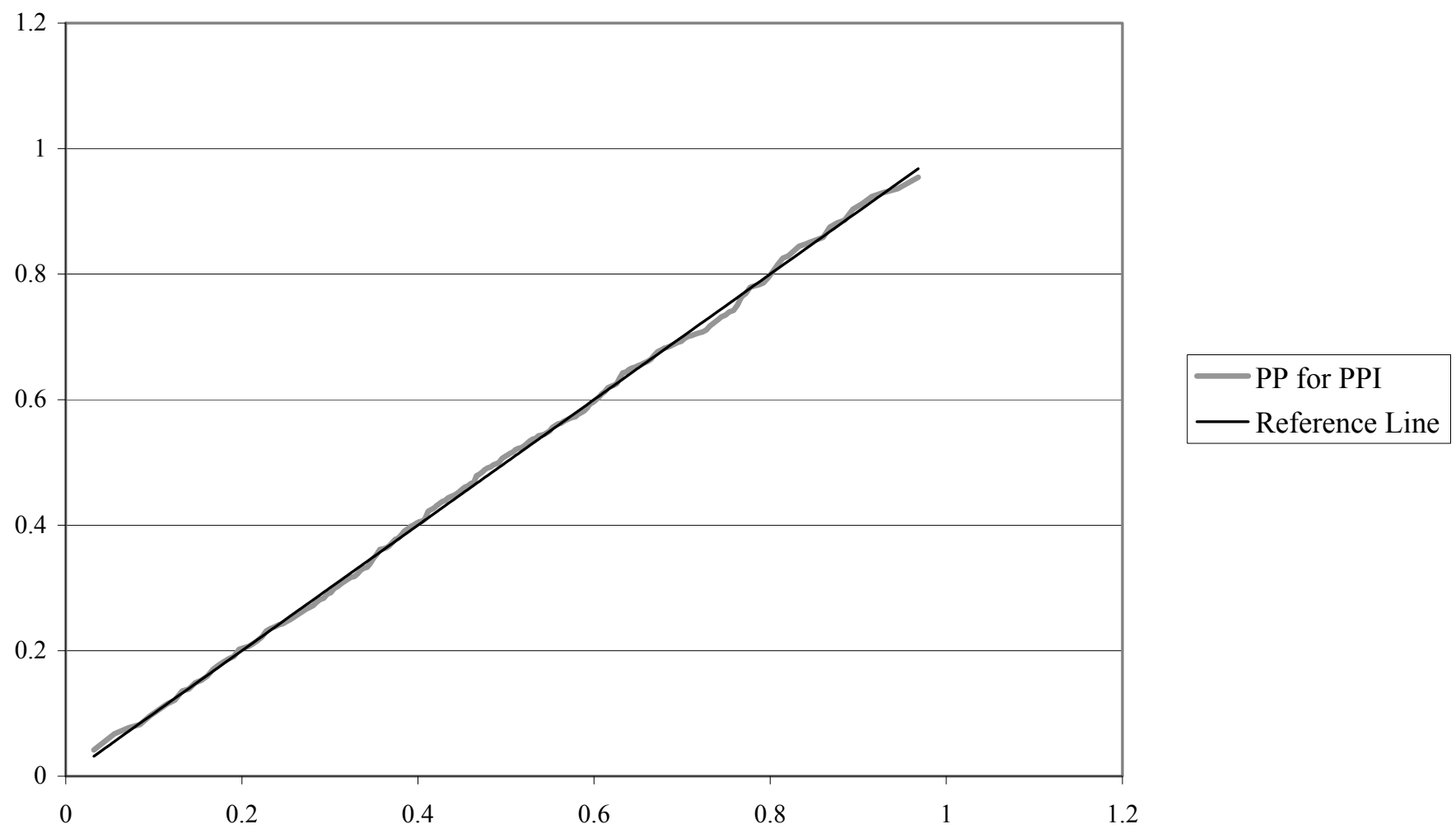


Figure 13. Variance-Stabilized PP Plot for Innovation in FFR Equation: AlphaStable Fit (ML Estimate)

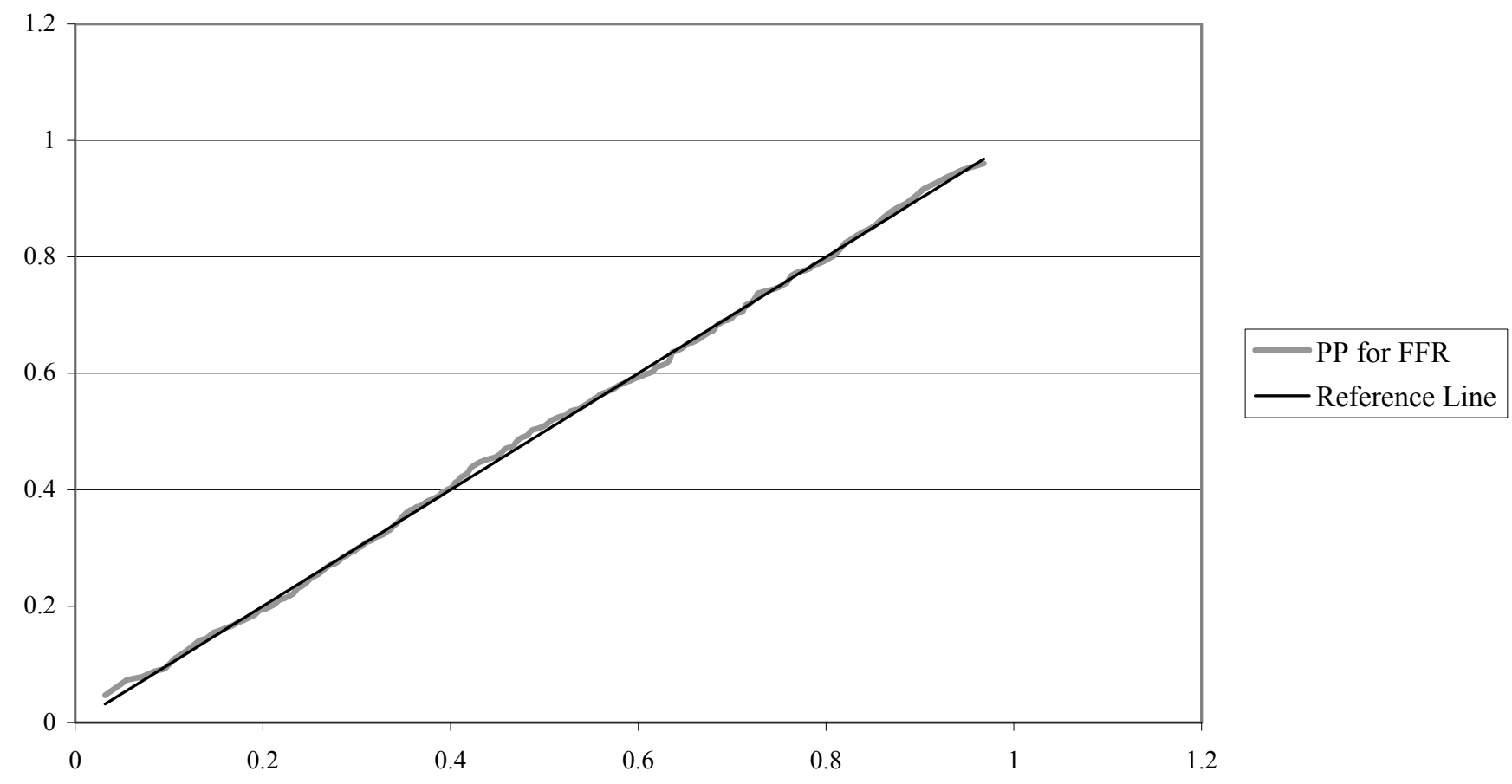


Figure 14. Variance-Stabilized PP Plot for Innovation in NBR Equation: Alpha-Stable Fit (ML Estimate)

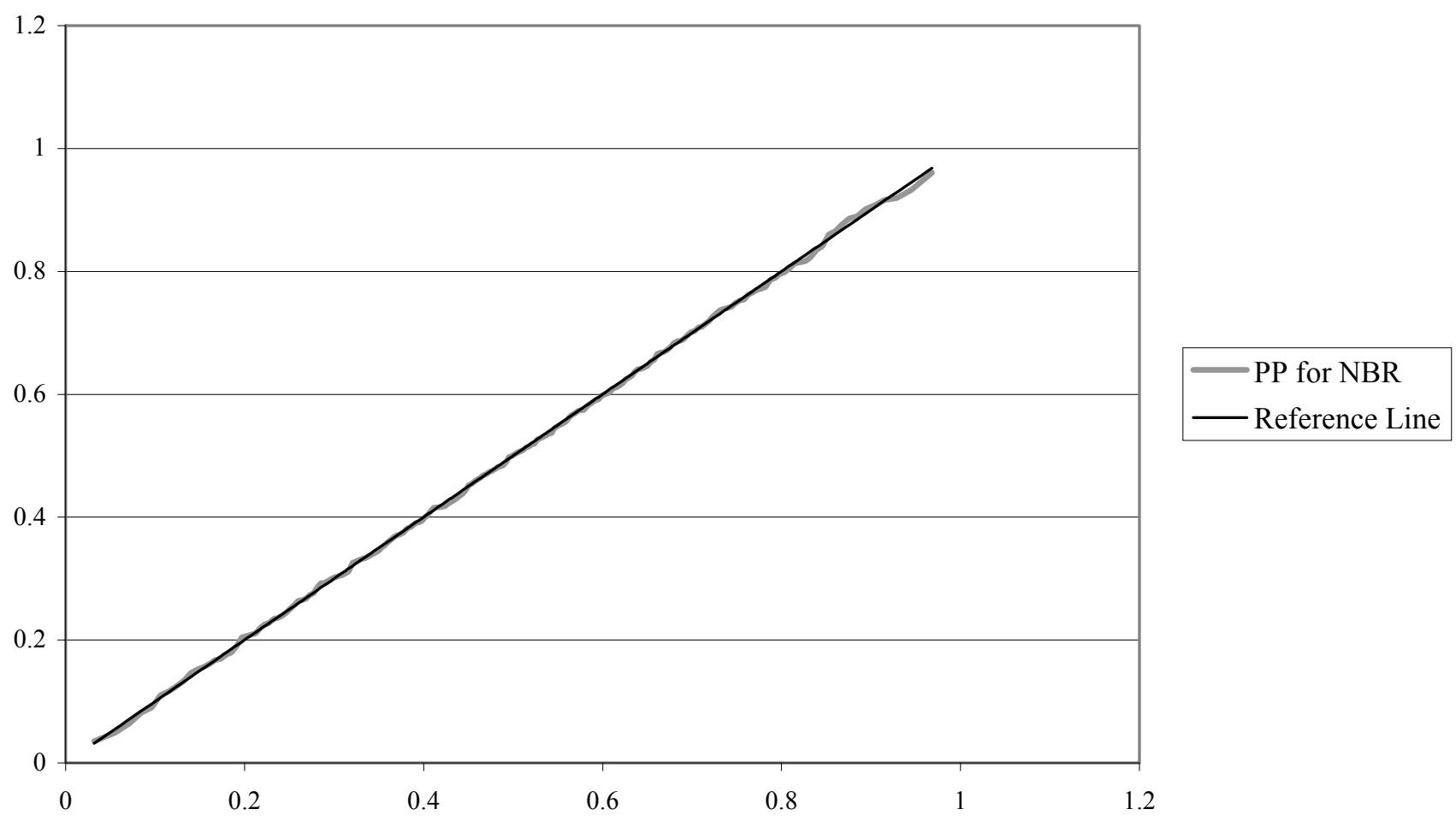


Figure 15. Variance-Stabilized P-P Plot for Innovation in TR Equation: AlphaStable Fit (ML Estimate)

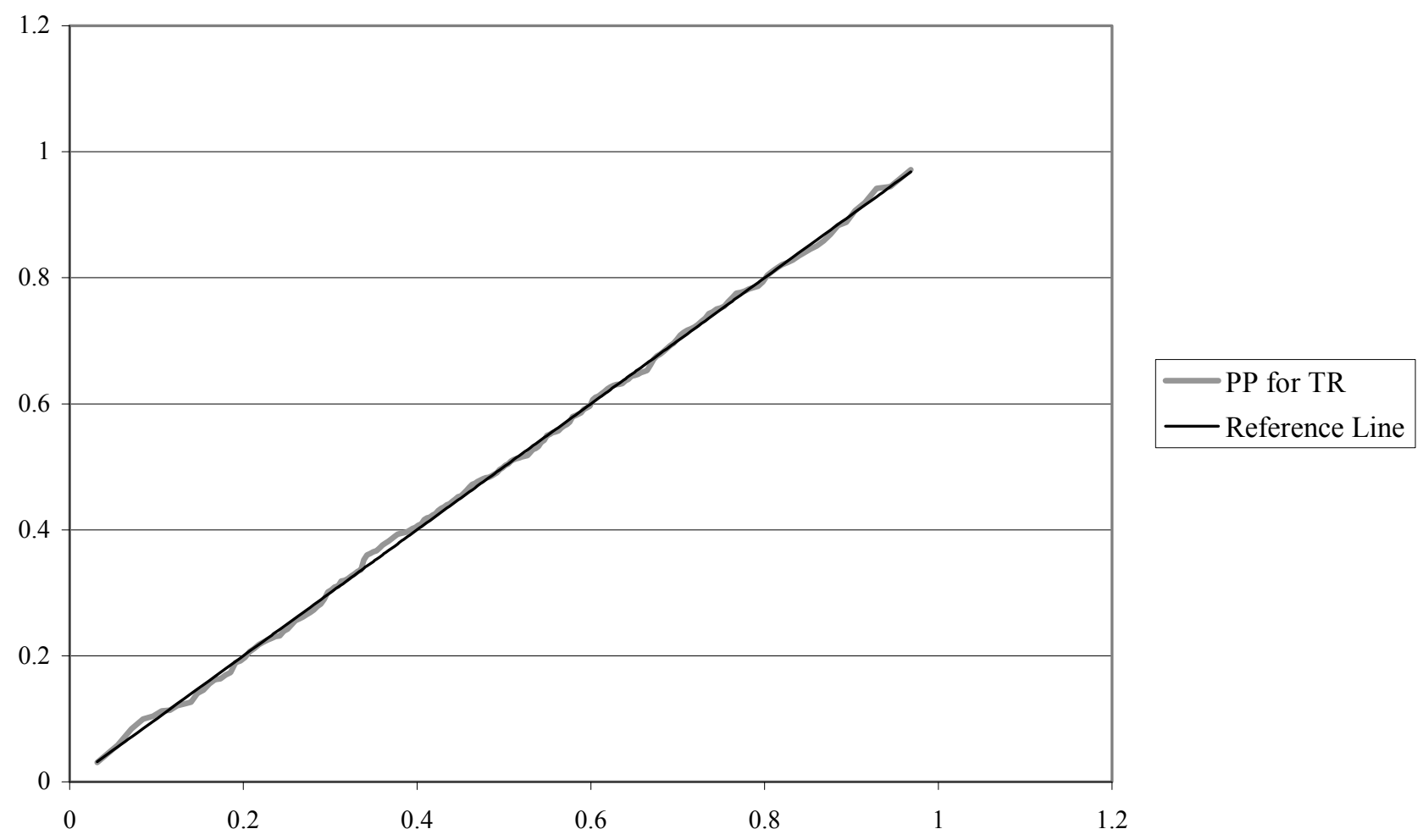


Table 1. Sample Statistics for Reduced-Form Innovations $\varepsilon_{t}{ }^{L S}$, 6-Variable Monetary

VAR, 1959:1-2007:11

IP Equation CPI Equation PPI Equation FFR Equation NBR Equation TR Equation

$\begin{array}{lllllll}\text { Std. Dev. } & 0.006249 & 0.001972 & 0.027257 & 0.443849 & 0.021413 & 0.019618 \\ \text { Skewness } & 0.022306 & 0.175226 & 0.070495 & -1.509032 & 2.794186 & 6.973937 \\ \text { Kurtosis } & 4.464086 & 6.285196 & 12.24979 & 35.74013 & 47.98869 & 123.6040 \\ \text { Jarque-Bera } & 51.40351 & 261.5130 & 2050.320 & 25899.56 & 49239.45 & 353142.5 \\ \text { Probability } & 0.000000 & 0.000000 & 0.000000 & 0.000000 & 0.000000 & 0.000000\end{array}$

Table 2. Engle Test for ARCH, 3 Lags in Test Equation, Sample Period 1959:1-2007:11

\begin{tabular}{|l|l|l|}
\hline Equation & $\mathrm{R}^{2}$ & $\mathrm{R}^{2} \mathrm{X} T$ \\
\hline $\mathrm{IP}$ & .051 & $29.172^{*}$ \\
\hline CPI & .091 & $52.052^{*}$ \\
\hline PPI & .123 & $70.356^{*}$ \\
\hline FFR & .061 & $34.892^{*}$ \\
\hline NBR & .025 & $14.300^{*}$ \\
\hline TR & .019 & $10.868^{*}$ \\
\hline
\end{tabular}

Table 3. Engle Test for ARCH, 12 Lags in Test Equation, Sample Period 1959:1-2007:11

\begin{tabular}{|l|l|l|}
\hline Equation & $\mathrm{R}^{2}$ & $\mathrm{R}^{2} \mathrm{X} \mathrm{T}$ \\
\hline $\mathrm{IP}$ & .071 & $39.973^{*}$ \\
\hline CPI & .109 & $61.367^{*}$ \\
\hline PPI & .131 & $73.753^{*}$ \\
\hline FFR & .137 & $77.131^{*}$ \\
\hline NBR & .025 & 14.075 \\
\hline TR & .019 & 10.697 \\
\hline
\end{tabular}

Table 4. Engle Test for ARCH, 3 Lags in Test Equation, Sample Period 1966:1-1979:9

\begin{tabular}{|l|l|l|}
\hline Equation & $\mathrm{R}^{2}$ & $\mathrm{R}^{2} \mathrm{X} \mathrm{T}$ \\
\hline $\mathrm{IP}$ & .012 & 1.944 \\
\hline CPI & .144 & $23.328^{*}$ \\
\hline PPI & .103 & $16.686^{*}$ \\
\hline FFR & .072 & $11.664^{*}$ \\
\hline NBR & .001 & .162 \\
\hline TR & .025 & 4.05 \\
\hline
\end{tabular}


Table 5. Engle Test for ARCH, 12 Lags in Test Equation, Sample Period 1966:1-79:9

\begin{tabular}{|l|l|l|}
\hline Equation & $\mathrm{R}^{2}$ & $\mathrm{R}^{2} \mathrm{X} \mathrm{T}$ \\
\hline $\mathrm{IP}$ & .047 & 7.191 \\
\hline CPI & .169 & $25.857^{*}$ \\
\hline PPI & .135 & 20.655 \\
\hline FFR & .124 & 18.972 \\
\hline NBR & .037 & 5.661 \\
\hline TR & .094 & 14.382 \\
\hline
\end{tabular}

Table 6. Engle Test for ARCH, 3 Lags in Test Equation, Sample Period 1988:4-2007:11

\begin{tabular}{|l|l|l|}
\hline Equation & $\mathrm{R}^{2}$ & $\mathrm{R}^{2} \mathrm{X} \mathrm{T}$ \\
\hline $\mathrm{IP}$ & .076 & $17.708^{*}$ \\
\hline CPI & .009 & 2.097 \\
\hline PPI (raw mat.) & .077 & $17.941^{*}$ \\
\hline FFR & .007 & 1.631 \\
\hline NBR & .001 & .233 \\
\hline TR & .001 & .233 \\
\hline
\end{tabular}

Table 7. Engle Test for ARCH, 12 Lags in Test Equation, Sample Period 1988:4-2007:11

\begin{tabular}{|l|l|l|}
\hline Equation & $\mathrm{R}^{2}$ & $\mathrm{R}^{2} \mathrm{X} \mathrm{T}$ \\
\hline $\mathrm{IP}$ & .104 & $23.296^{*}$ \\
\hline CPI & .040 & 8.960 \\
\hline PPI & .085 & 19.040 \\
\hline FFR & .020 & 4.480 \\
\hline NBR & .001 & .224 \\
\hline TR & .001 & .224 \\
\hline
\end{tabular}


Table 8. Estimates of $\alpha$ for Innovations in Six-Variable VAR for 1959:1-2007:11

\begin{tabular}{|l|l|l|}
\hline Equation & Estimator & $\begin{array}{c}\text { Characteristic } \\
\text { Exponent } \\
\text { Estimate }(\alpha) \\
(1.96 \text { times } \\
\text { asymptotic } \\
\text { S.E.) }\end{array}$ \\
\hline IP & Quantile & 1.6875 \\
\hline & Char. function & 1.8664 \\
\hline CPI & ML & $1.7734(.1165)$ \\
\hline & Quantile & 1.7280 \\
\hline PPI & Char. Function & 1.8189 \\
\hline & ML & $1.7325(.1208)$ \\
\hline & Quantile & 1.5987 \\
\hline FFR & Char. Function & 1.6141 \\
\hline & ML & $1.5504(.1265)$ \\
\hline & Quantile & 1.5668 \\
\hline NBR & Char. Function & 1.5884 \\
\hline & ML & $1.5623(.1295)$ \\
\hline & Quantile & 1.7167 \\
\hline TR & Char. Function & 1.7391 \\
\hline & ML & $1.7201(.1221)$ \\
\hline & Quantile & 1.6864 \\
\hline & Char. Function & 1.7543 \\
\hline & ML & $1.7606(.1180)$ \\
\hline & & \\
\hline & & \\
\hline & & \\
\hline & & \\
\hline & &
\end{tabular}


Table 9. Estimated Characteristic Exponents ( $\alpha$ ) for 1966:1-79:9 Subsample

\begin{tabular}{|l|l|l|}
\hline Equation & Estimator & $\begin{array}{c}\text { Characteristic } \\
\text { Exponent } \\
\text { Estimate }(\alpha) \\
(1.96 \text { times } \\
\text { asymptotic } \\
\text { S.E. })\end{array}$ \\
\hline IP & Quantile & 1.8892 \\
\hline & Char. function & 1.9626 \\
\hline CPI & ML & $2.0000(\#)$ \\
\hline & Quantile & 1.7983 \\
\hline PPI & Char. Function & 1.8648 \\
\hline & ML & $1.8557(.1869)$ \\
\hline & Quantile & 1.5987 \\
\hline FFR & Char. Function & 1.8071 \\
\hline & ML & $1.7351(.2241)$ \\
\hline & Quantile & 1.6319 \\
\hline NBR & Char. Function & 1.8449 \\
\hline & ML & $1.7630(.2166)$ \\
\hline & Quantile & 1.8935 \\
\hline TR & Char. Function & 1.9432 \\
\hline & ML & $1.8673(.1815)$ \\
\hline & Quantile & 1.9271 \\
\hline & Char. Function & 1.9813 \\
\hline & ML & $2.0000(\#)$ \\
\hline
\end{tabular}

Notes: \# Confidence interval not available for IP and TR because standard asymptotic distribution theory does not apply at $\alpha=2$.

Results for residuals that were homoskedastic according to the tests reported in tables 4 and 5 are shown with a gray background. 
Table 10. Estimated Characteristic Exponents ( $\alpha$ ) for 1988:4-2007:11 Subsample

\begin{tabular}{|l|l|l|}
\hline Equation & Estimator & $\begin{array}{c}\text { Characteristic } \\
\text { Exponent } \\
\text { Estimate }(\alpha) \\
(1.96 \text { times } \\
\text { asymptotic } \\
\text { S.E. })\end{array}$ \\
\hline IP & Quantile & 2.0000 \\
\hline & Char. Function & 1.9401 \\
\hline CPI & ML & $1.8807(.1489)$ \\
\hline & Quantile & 1.8258 \\
\hline & Char. Function & 1.8773 \\
\hline PPI & ML & $1.8581(.1559)$ \\
\hline & Quantile & 1.7713 \\
\hline FFR & Char. Function & 1.8619 \\
\hline & ML & $1.8520(.1595)$ \\
\hline & Quantile & 1.7428 \\
\hline NBR & Char. Function & 1.9431 \\
\hline & ML & $1.9046(.1401)$ \\
\hline & Quantile & 1.8169 \\
\hline TR & Char. Function & 1.7341 \\
\hline & ML & $1.7588(.1839)$ \\
\hline & Quantile & 1.7204 \\
\hline & Char. Function & 1.7121 \\
\hline
\end{tabular}

Notes: Results for residuals that were homoskedastic according to the tests reported in tables 6 and 7 are shown with a gray background. 


\section{RESULTS FROM GARCH(1,1) MODEL}

Table 11. Estimated Coefficients for GARCH(1,1) Model (7) of Shocks from 6-Variable VAR, Full Sample*

$\begin{array}{llll}\text { Variance } & \text { Variable } & \begin{array}{l}\text { QML Coef. } \\ \text { Equation for }\end{array} & \text { S.E.** } \\ \text { IP residual } & \text { Constant } & 2.22 \mathrm{E}-05 & 7.11 \mathrm{E}-06 \\ & \text { Resid(-1)^2 } & .2126 & .0712 \\ & \text { GARCH(-1) } & .2140 & .1945 \\ \text { CPI residual } & \text { Constant } & 1.04 \mathrm{E}-06 & 3.24 \mathrm{E}-07 \\ & \text { RESID(-1)^2 } & .1688 & .0741 \\ & \text { GARCH(-1) } & .5621 & .1145 \\ \text { PPI residual } & \text { Constant } & 2.76 \mathrm{E}-05 & 1.14 \mathrm{E}-05 \\ & \text { Resid(-1)^2 } & .2544 & .0855 \\ & \text { GARCH(-1) } & .7339 & .0627 \\ \text { FFR residual } & \text { Constant } & .0075 & .0029 \\ & \text { RESID(-1)^2 } & .2754 & .1198 \\ & \text { GARCH(-1) } & .7062 & .0800 \\ \text { NBR residual } & \text { Constant } & 3.07 \mathrm{E}-05 & 1.39 \mathrm{E}-05 \\ & \text { Resid(-1)^2 } & .6979 & .3830 \\ & \text { GARCH(-1) } & .5499 & .0359 \\ \text { TR residual } & \text { Constant } & 1.14 \mathrm{E}-05 & 1.70 \mathrm{E}-05 \\ & \text { RESID(-1)^2 } & .7858 & .5580 \\ & \text { GARCH(-1) } & .5879 & .0312\end{array}$

Notes: *Presample variances computed using backcasting parameter $=0.7$

$* *$ S.E. $=$ Bollerslev-Wooldridge (1992) robust standard error 
Table 12. Estimates of $\alpha$ for GARCH(1,1)-Filtered Innovations* in 6-Variable VAR, Full Sample

\begin{tabular}{|l|l|l|}
\hline Equation & Estimator & $\begin{array}{c}\text { Characteristic } \\
\text { Exponent } \\
\text { Estimate }(\alpha) \\
(1.96 \text { times } \\
\text { asymptotic } \\
\text { standard error). }\end{array}$ \\
\hline IP & Quantile & 1.6155 \\
\hline & Char. function & 1.8594 \\
\hline CPI & ML & $1.7638(.1174)$ \\
\hline & Quantile & 1.9774 \\
\hline PPI & Char. Function & 1.8672 \\
\hline & ML & $1.7969(.1129)$ \\
\hline & Quantile & 2.0000 \\
\hline FFR & Char. Function & 1.9412 \\
\hline & ML & $1.8897(.0934)$ \\
\hline & Quantile & 2.0000 \\
\hline NBR & Char. Function & 1.8553 \\
\hline & ML & $1.8512(.1015)$ \\
\hline & Quantile & 1.5419 \\
\hline TR & Char. Function & 1.7918 \\
\hline & ML & $1.8073(.1108)$ \\
\hline & Quantile & 1.6913 \\
\hline & Char. Function & 1.7800 \\
\hline & ML & $1.7551(.1189)$ \\
\hline
\end{tabular}

* Estimated GARCH(1,1) parameters shown in table 11, above. 